GEAP-13603

AEC RESEARCH AND

DEVELOPMENT REPORT

NOVEMBER 1970

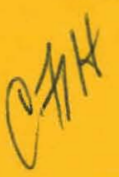

\title{
CENTER TEMPERATURE MEASUREMENTS OF MIXED OXIDE FUEL ZERO TO 3,000 MWd/Te
}

R. R. ASAMOTO

P. E. BOHABOY

D. W. SANDUSKY

A. E. CONTI

U.S. ATOMIC ENERGY COMMISSION CONTRACT AT (04-3)-189

PROJECT AGREEMENT 10

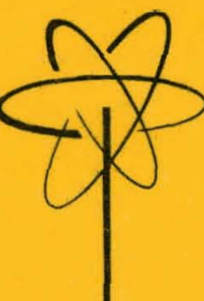




\section{DISCLAIMER}

This report was prepared as an account of work sponsored by an agency of the United States Government. Neither the United States Government nor any agency Thereof, nor any of their employees, makes any warranty, express or implied, or assumes any legal liability or responsibility for the accuracy, completeness, or usefulness of any information, apparatus, product, or process disclosed, or represents that its use would not infringe privately owned rights. Reference herein to any specific commercial product, process, or service by trade name, trademark, manufacturer, or otherwise does not necessarily constitute or imply its endorsement, recommendation, or favoring by the United States Government or any agency thereof. The views and opinions of authors expressed herein do not necessarily state or reflect those of the United States Government or any agency thereof. 


\section{DISCLAIMER}

Portions of this document may be illegible in electronic image products. Images are produced from the best available original document. 


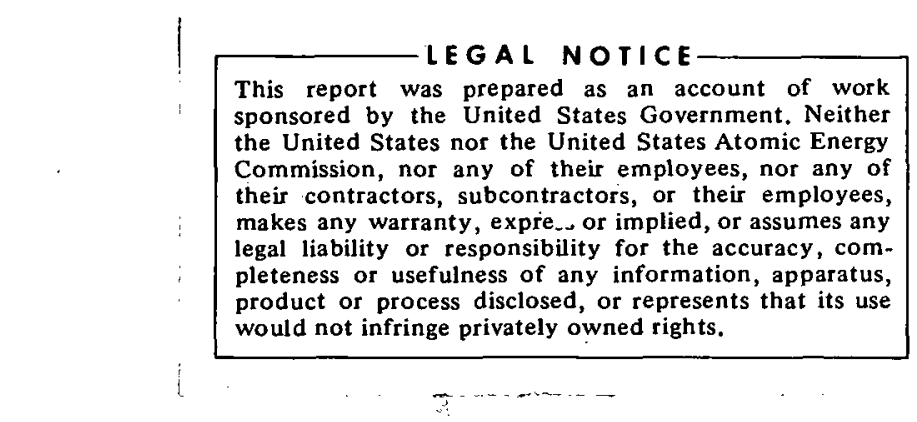

A. 2.m.

GEAP- 13603

AEC Research and

Development Report

November 1970

\title{
CENTER TEMPERATURE MEASUREMENTS OF MIXED OXIDE FUEL FROM ZERO TO $3,000 \mathrm{MWd} / \mathrm{Te}$
}

\author{
R. R. Asamoto \\ P. E. Bohaboy \\ D. W. Sandusky \\ A. E. Conti \\ Approved: W.tilsacles \\ W. E. Baily, Project Engineer \\ Fast Ceramic Reactor Development Program \\ Approved: \\ Prepared for the \\ United States Atomic Energy Commission \\ Under \\ Contract No. AT(04-3)-189, Project Agreement No. 10 \\ Printed in U.S.A. Available from the \\ Clearing House for Federal Scientific and Technical Information \\ Nativiral Burcau of Standaru's; U.S. Department of Commerce \\ Springfield, Virginia \\ Price: $\$ 3.00$ per copy

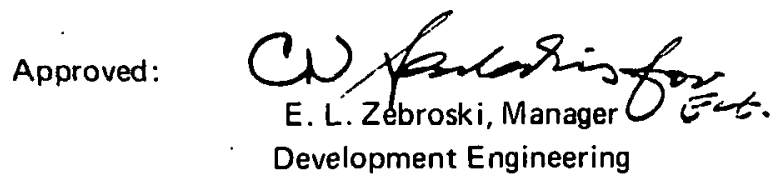

Development Engineering 


\section{LEGAL NOTICE}

This report was prepared as an account of Government sponsored work. Neither the United States, nor the Commission, nor any person acting on bebalf of the Commission:

A. Makes any warranty or representation, expressed or implied, with respect to the accuracy, completeness, or usefulness of the information contained in this report, or that the use of any information, apparatus, method, or process disclosed in this report may not infringe privately owned rights; or

B. Assumes any liabilities with respect to the use of, or for damages resulting from the use of any information, apparatus, method, or process disclosed in this report."

As used in the above, "person acting on bebalf of the Commission" includes any employee or contractor of the Commission, or employee of such contractor, to the extent that such employee or contractor of the Commission, or employee of such contractor prepares, disseminates, or provides access to, any information pursuant to his employment or contract with the Commission, or his employment with such cotitractor.

LN-1 


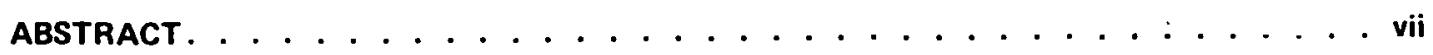

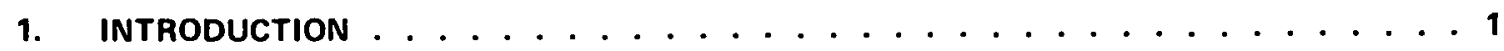

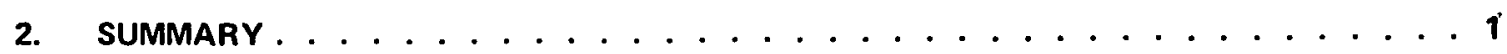

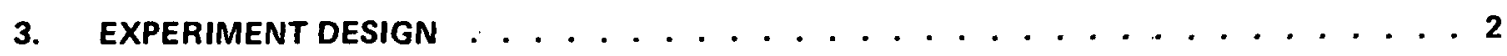

3.1 Fuel Pin Design . . . . . . . . . . . . . . . . . . . . . . . 2

3.2 Capsule Design . . . . . . . . . . . . . . . . . . . . . . . . . . . . 2

3.3 Irradiation Facility and Operational History . . . . . . . . . . . . . 2

4. TEST RESULTS . . . . . . . . . . . . . . . . . . . . . . . 9

4.1 Linear Power Calculations . . . . . . . . . . . . . . . . . . . 9

4.2 Fuel Clad Surface Temperatures . . . . . . . . . . . . . . . . . . . . . . . 11

4.3 Fuel Integral Conductivity and Fuel-Cladding Gap Coefficients . . . . . . . . . . . . 14

4.4 Post-Irradiation Examination . . . . . . . . . . . . . . . . . . . . . . . . . . 14

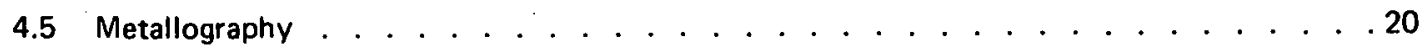

4.6 Post-Irradiation Thermocouple Calibration . . . . . . . . . . . . . . 26

5. DISCUSSION OF RESULTS. . . . . . . . . . . . . . . . . 28

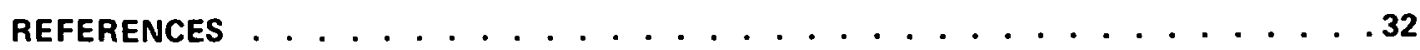

APPENDIX

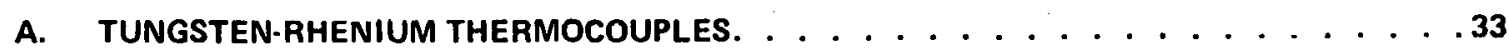

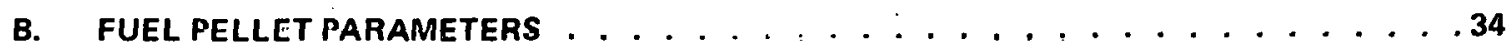

C. THERMAL CONDUCTIVITY CURVES FOR 304 SS, 316 SS, 321 SS, Zircaloy-2 AND NaK. . . 36

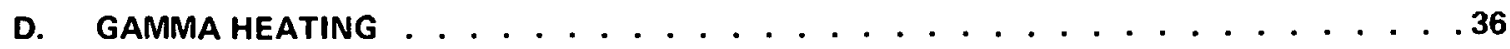

E. DETERMINATION OF FUEL Clad SURFACE TEMPERATURE . . . . . . . . . . 37

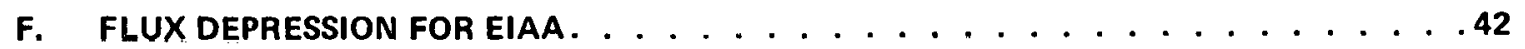

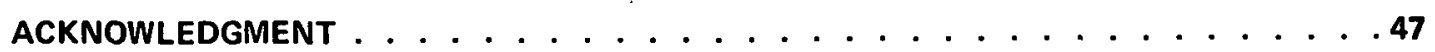

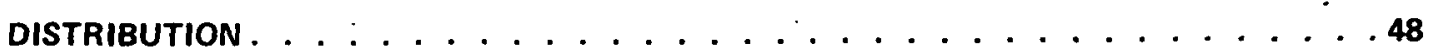




\section{LIST OF ILLUSTRATIONS}

Title

Page

3-1

EIAA Fuel Pin Drawing . . . . . . . . . . . . . . . . . . . . . . . . . . . . 3

3-2

Typical Mixed Oxide Pellets Used in Capsule E1AA . . . . . . . . . . . . . . . . . 4

Radial Cross-Section of Capsule E1AA . . . . . . . . . . . . . . . . . . . . . . 5

3-4

1/16 Inch and 20 Mil o.d. Chromel-Alumel Thermocouples Around Fuel Pin Cladding . . 6

3-5a

Irradiation History of Capsule E1AA-GETR Cycle 97 . . . . . . . . . . . . . . 7

3-5b

4-1

Irradiation History of Capsule E1AA-GETR Cycle 98 . . . . . . . . . . . . . . . . . . . . . 8

4-2

Interfaces between Thermocouples No. 4 and 6 . . . . . . . . . . . . . . . . . 10

4-3

Linear Power Versus Fuel Temperature (Center) and Time . . . . . . . . . . ... . . 12

Increase in Fuel Center Temperature During Constant Linear Power Operation . . . . . 13

4-4 Integral Conductivity Cure $\left(\mathrm{Pu}_{0.2} \mathrm{u}_{0.8}\right) \mathrm{O}_{2.00}$ Above $500^{\circ} \mathrm{C}$. . . . . . . . . . . . . . . 15

4.5 Fuel-Cladding Gap Coefficients . . . . . . . . . . . . . . . . . . . . . . . . 16

4-6 Fuel Integral Conductivity Values at Various Irradiation Times . . . . . . . . . . . . 17

4.7 Capsule E1AA Gross Gamma Scan . . . . . . . . . . . . . . . . . . . . . . . . 18

4-8 Post-Irradiation Contact of Chromel-Alumel Thermocouple (No. 18) with Fuel Pin Cladding 19

4.9 Fuel Pin E1AA Sectioning Diagram . . . . . . . . . . . . . . . . . . . . . . . 21

4-10 Autoradiographs of E1AA Fuel Pin . . . . . . . . . . . . . . . . . . . . . . 22

4-11 Diametral Composites of Central Fuel Zones . . . . . . . . . . . . . . . . . . . . 23

4-12 Post-Irradiation Fuel Annulus of Section "F" . . . . . . . . . . . . . ......... . . 24

4-13 Fuel Cladding Interaction . . . . . . . . . . . . . . . . . . . . . . . . . . 25

4-14 Cladding in the Etched Condition . . . . . . . . . . . . . . . . . . . . . . . 25

4-15 Calibration Data of Irradiated W5Re/W26Re Thermocouples . . . . . . . . . . . . . 27

5-1 Relationship Between Fuel Cladding Surface.Temperature and Linear Power . . . . . ' . 29

5-2 Temperature Profiles Across Fuel Operating at $15 \mathrm{~kW} / \mathrm{ft}$. . . . . . . . . . . . . . . . 31

E-1 Relation of Outer Thermocouples Next to Fuel Cladding . . . . . . . . . . . . . . 38

E-2 Relation of Outer Thermocouples to a 20 Mil Thermocouple Next to the Fuel Cladding: . 39

E-3 Cladding Surface Temperature Determined Using a $20 \mathrm{Mil}$ and $62 \mathrm{Mil}$ Thermocouple $\quad . \quad 40$

E-4 Cladding Temperature Related to Thermocouple Temperature . . . . . . . . . . . . 41

F.1 E1AA Self Shielding Factor $R=0.1095$ inch _.... . . . . . . . . . . . . . . . . 45

F-2 Power Shape Factor for E1AA . . . . . . . . . . . . . . . . . . . . . . . . . 46 


\section{LIST OF TABLES}

3-1 Fuel Pin Parameters . . . . . . . . . . . . . . . . . . . . . . . 9

4-1 Fission Gas Analysis . . . . . . . . . . . . . . . . . . . . . . . . . . . 20

A-1 Typical Chemical Analysis of Ultra-High-Purity (99.9 Percent) BeO . . . . . . . . . 33

A-2 Calibration Data for Tungsten-Rhenium Thermocouples . . . . . . . . . . . . 33

B.1 Isotopic Distribution of Fuel Batches and Stoichiometry of Sintered Pellets Utilized in Capsule EIAA . . . . . . . . . . . . . . . . . . . . . . . . . . 34

B-2 Specific Parameters of Pellets in Fuel Pin E1AA . . . . . . . . . . . . . . . . . . 34

B-3 Fuel Column Length. . . . . . . . . . . . . . . . . . . . . . . . . . . 35

E-1 Comparison of Fuel Clad Temperatures Predicted by. Calculation and a Geometric Approach .......................... . . 4 42 


\begin{abstract}
The center temperature and the power output of an encapsulated plutonium-uranium oxide fuel pin was directly measured during irradiation in GETR. Linear powers up to $15 \mathrm{~kW} / f \mathrm{t}$ and central temperatures to $2100^{\circ} \mathrm{C}$ were measured during the experiment which extended to $3000 \mathrm{MWd} / \mathrm{Te}$.

The experimental results indicate (1) a decrease in the effective thermal conductivity when the fuel pin is thermally cycled at center temperatures below $1650^{\circ} \mathrm{C}$, and (2) a gradual decrease in the heat transfer properties with increasing fuel burnups to $3000 \mathrm{MWd} / \mathrm{Te}$. The first effect is attributed to irradiation damage and thermally induced cracking in the fuel which decreases the effective heat flow. This decrease disappears when the central temperature is increased to temperatures where fuel restructuring is possible. The second effect resulted in increased fuel center temperatures of 100 to $200^{\circ} \mathrm{C}$ when compared to fuel with essentially zero burnup. This relationship was noted for all linear powers to $15 \mathrm{~kW} / \mathrm{ft}$ and for fuel center temperatures to $2100^{\circ} \mathrm{C}$.
\end{abstract}

-vii-/-viii- 


\section{INTRODUCTION}

Mixed plutonium-uranium oxides are a prime candidate fuel for the liquid metal fast breeder reactor. Their use requires a thorough knowledge of the material's physical properties, including its heat transfer characteristics. The direct measurement of these characteristics during operation of the fuel is difficult for three reasons. First, temperatures inside a fuel pin are difficult to measure, and thermocouple calibration is affected by radiation. Second, the heat delivered by each part of the fuel is influenced by the shielding of the other parts. Third, the temperature drop across the fuel-cladding gap cannot be determined to a high precision.

The purpose of this experiment was to obtain direct measurements of the thermal performance of $\left(\mathrm{Pu}_{0.2} \mathrm{U}_{0.8}\right)_{\mathrm{O}_{1.97}}$ fuel in a typical reactor environment and to determine any changes in properties with linear power and burnup.

Numerous attempts have been made to measure indirectly the effective thermal conductivity of oxide fuel pins. However, only a few experiments have been successful in obtaining a direct reading by placing temperature sensing devices in the fuel column. Christensen and Allio ${ }^{1 .}$ used tungsten-rhenium thermocouples located at various radial fuel positions to measure the temperature distribution in irradiated $\mathrm{UO}_{2}$ up to center temperatures of $2150^{\circ} \mathrm{C}$. Coplin, et al. ${ }^{2}$ used a gas bulb thermometer to monitor $\mathrm{UO}_{2}$, fuel center temperatures to $2750^{\circ} \mathrm{C}$. In an earlier experiment under this program, the center fuel temperature of a mixed plutonium-uranium oxide fuel pin in a thermal flux environment was monitored directly with both a tungsten-rhenium thermocouple and a gas bulb thermometer. ${ }^{3} 4$ No significant conductivity change was noted during that 400 hour irradiation. The present experiment attempted to improve on the previously reported data by monitoring more precisely the fuel pin linear power and comparing this parameter with the corresponding fuel center temperature.

\section{SUMMARY}

The center temperature and the power output of an encapsulated plutonium-uranium oxide fuel pin was directly measured during irradiation in GETR. Linear powers up to $15 \mathrm{~kW} / \mathrm{ft}$ and central temperatures to $2100^{\circ} \mathrm{C}$ were measured during the experimerit whicli extended to $3000 \mathrm{MWd} / \mathrm{Te}$.

The thermal conductivity of the fuel, the cladding surface temperatures, and operating linear powers were all calculated from temperature data obtained during irradiation. Tungsten-rhenium thermocouples were used to measure fuel center temperatures to $2100^{\circ} \mathrm{C}$, while chromel-alumel thermocoupies were employed to obtain temperature data at varlous radial and axial positions outside the fuel pin.

For the first 120 hours of thermal flux irradiation, fuel center temperatures were maintained below $1650^{\circ} \mathrm{C}$. The experimental data indicated that the effective thermal conductivity of the $\left(\mathrm{Pu}_{0.2} \mathrm{U}_{0.8}\right)_{1.9}$ fuel decreased during this period. This decrease was attributed to: (1) irradiation damage to the fuel (effect on conductivity is greatest below $1000^{\circ} \mathrm{C}$ ); and (2) the formation of cracks in the fuel resulting from thermal stresses. The effective decrease in heat transfer within the fuel pin resulted in fuel center temperatures increasing an average of $100^{\circ} \mathrm{C}$ from initial values for a given linear power. This desrease in heat transfer characteristic was apparently eliminated or minimized when the fuel temperature was increased above $1650^{\circ} \mathrm{C}$. Under these thermal conditions, annealing of irradiation damage in the fuel and closing of cracks due to fuel thermal expansion occurred.

With increasing fuel burnup (up to $\sim 3000 \mathrm{MWd} / \mathrm{Te}$, 280 hours of irradiation), a gradual rise in the fuel center temperature from $2000^{\circ}$ to $2100^{\circ} \mathrm{C}$ was noted, while operating at a constant power of $15 \mathrm{~kW} / \mathrm{ft}$. Similar increases of 100 to $200^{\circ} \mathrm{C}$ in the center temperature were required to maintain any linear power between 7 and $15 \mathrm{~kW} / \mathrm{ft}$. as produced by that fuel at essentially zero burnup. Assuming that the fuel-gap conductivity remained constant aluriy with no thermocouple decalibration, the possible factors contributing to the increased center temperature include tuel stoichiometry shifts, fission product buildup, and formation of a radial plutonium gradient within the fuel. Densification of the fuel would increase the thermal conductivity. A quantitative evaluation of the above phenomena is impossible because of the lack of sufficient thermal conductivity data on plutonium-uranium oxides, and the large uncertainties irivolved with the assumption made.

A post-irradiation check of irradiated tungstenrhenium thermocouples indicated a réduction in emf output with temperature. This apparent decalibration suggests that the increase in the fuel center temperature with burnup may have been slightly greater than the data indicated. 


\section{EXPERIMENT DESIGN}

\subsection{FUEL PIN DESIGN}

The 316 stainless steel fuel pin cladding was 0.250 inches in diameter by 9.5 inches long, and contained annular $\left(\mathrm{Pu}_{0.2} \mathrm{U}_{0.8}\right) \mathrm{O}_{1.9}$ fuel, Figure 3-1. Three 1/4-inch long $\mathrm{UO}_{2}$ pellets were located at both the top and bottom of the 6 -inch column of fuel to provide insulation. These insulator pellets were sandwiched between 1/4-inch long stainless steel dummy pellets, which provided a guide for inserting the tungsten-rhenium thermocouples. A 1 -inch long fission gas plenum was designed at the top of the fuel pin, and contained a stainless steel retainer spring (spring constant of $3.1 \mathrm{lb} / \mathrm{in}$.). The spring was compressed approximately $1 / 16$ inch and so exerted a force of about $0.2 \mathrm{lb}$, or a stress of about 5 psi on the fuel. Two 1/16-inch o.d., W5Re/W26Re thermocouples were inserted 2 inches into the mixed oxide fuel column, one from the top and the other from the bottom of the fuel pin. Details of the W/Re thermocouples are discussed in Appendix A. The fuel pin was sealed in a high purity helium $(99.995 \% \mathrm{He})$ atmosphere.

The mixed oxide powder was made by the coprecipitation of plutonium hydroxide and ammonium diuranate from a solution of uranium and plutonium nitrate. The plutonium-uranium oxide powder was pre-pressed at about $35 \mathrm{tsi}$, granulated, and pressed into annular pellets at about $10 \mathrm{tsi}$. The pellets were then sintered for $2-1 / 2$ hours at $1600^{\circ} \mathrm{C}$ in a helium-6\% hydrogen atmosphere. Typical fabricated pellets are shown in Figure 3-2, and pertinent fuel and fuel pin parameters are listed in Table 3-1. Detailed fuel parameters are listed in Appendix B.

\subsection{CAPSULE DESIGN}

The capsule design consisted of concentric stainless steel and Zircaloy tubes located around the fuel pin, which acted as both containments and thermal barriers. Standard chromel-alumel thermocouples (1/16 inch o.d. and 20-mil o.d.) were strapped to the outside of each containment, while the annulii formed by the tubes were filled with Nak. Figure 3-3 shows a detailed cross section of the capsule and the location of each of the thermocouples. "Sets" of thermocouples were positioned in such a manner that linear power values could be calculated on a given radial plane from the center of the fuel to the outer containment. (A "set" comprises the three thermocouples at one angular position, excluding the center thermocouples; e.g. 3, 4, and 6.) Two sets of the chromel-alumel thermocouples were located on each of the two horizontal planes defined by the hot junction of each of the tungsten-rhenium thermocouples.

Thermocouples were securely held in place with a stainless steel band as shown in Figure 3-4. These bands were placed near the hot junction of the thermocouples to assure good contact with the stainless steel or Zircaloy surface. A stainless steel insert was placed around the 20-mil thermocouples so that the band would secure them firmly along with adjacent 1/16 inch o.d. thermocouples.

Six nonfunctional W5Re/W26Re thermocouples were placed in aluminum tubes and positioned outside the capsule. Following the irradiation, these thermocouples were used to measure any decalibration in the thermoelectric output caused by the accumulated neutron fluence.

\subsection{IRRADIATION FACILITY AND OPERATIONAL HISTORY}

Capsule E1AA was irradiated in the General Electric Test Reactor (GETR) pool in a Mark IV-A V-Raft. The capsule was placed in a facility tube allowing both radial and vertical positioning during reactor operation. The irradiation history of the capsule during GETR cycles 97 and 98 is shown in Figures 3.5a and 3.5b. Outputs from thermocouples No. 1 (W/Re) and No.6 (20-mil diameter $\mathrm{Cr} / \mathrm{Al}$ ) and reactor power have been plotted as a function of time. During the irradiation period, the capsule experienced 11 reactor scrams.

The total neutron flux seen by the capsule was as follows:

Fast $(>0.18 \mathrm{MeV})=0.53 \times 10^{20}$ neutrons $/ \mathrm{cm}^{2}$ Epithermal $(0.17 \mathrm{eV}<\mathrm{E}<0.18 \mathrm{MeV})=2.1 \times 10^{20}$ neutrons $/ \mathrm{cm}^{2}$ Thermal $(<0.17 \mathrm{eV})=1.9 \times 10^{20}$

The total fuel burnup at the end of irradiation (based on physics calculations) was $17,300 \mathrm{MWd} / \mathrm{Te}$. 


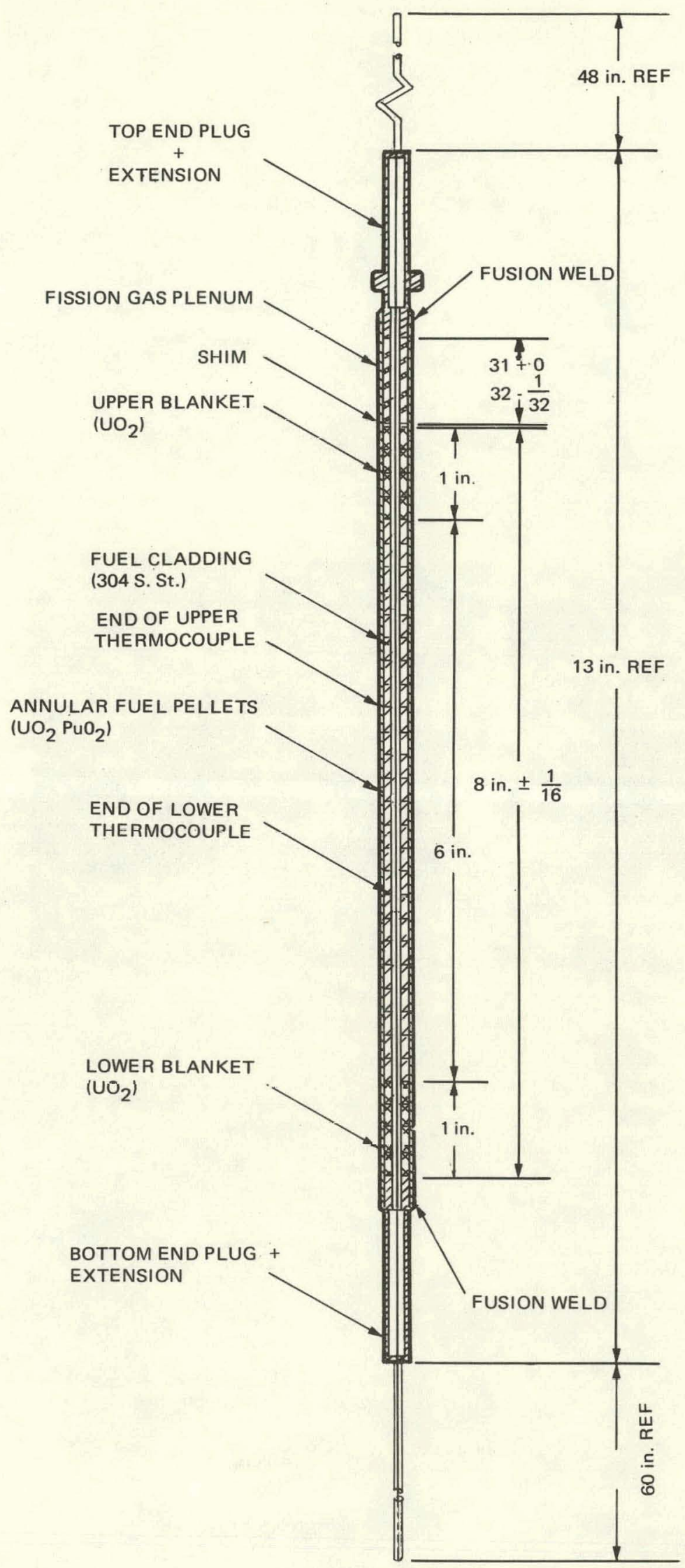

Figure 3-1. E1AA Fuel Pin Drawing 


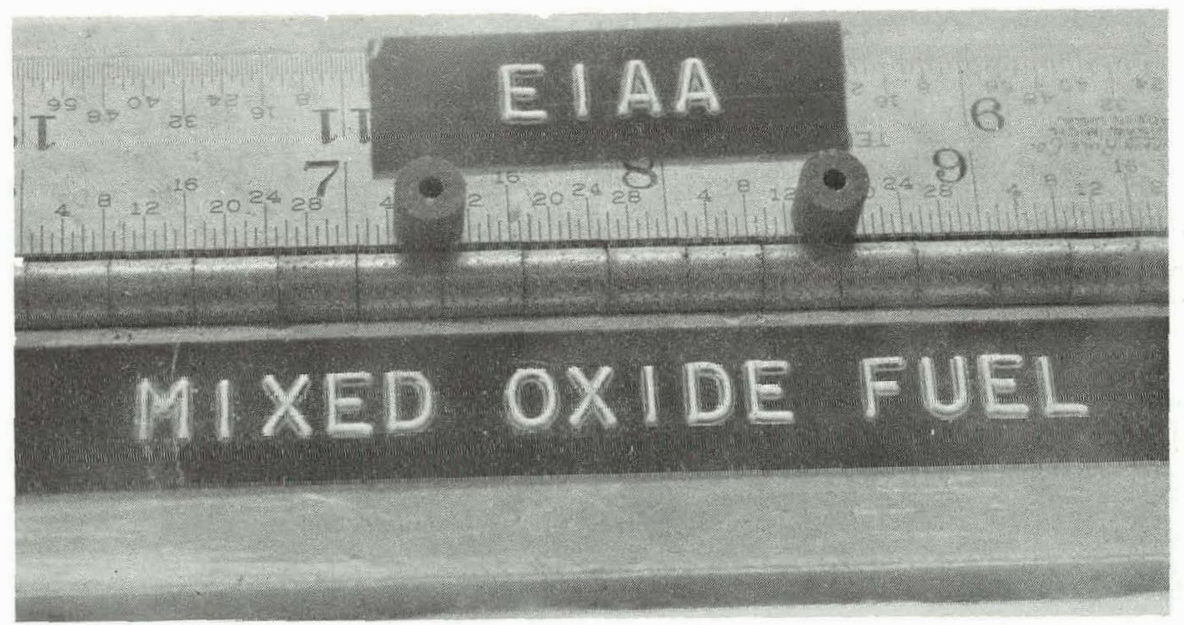

NEG NO. 46285

Figure 3-2. Typical Mixed Oxide Pellets Used in Capsule E1AA 


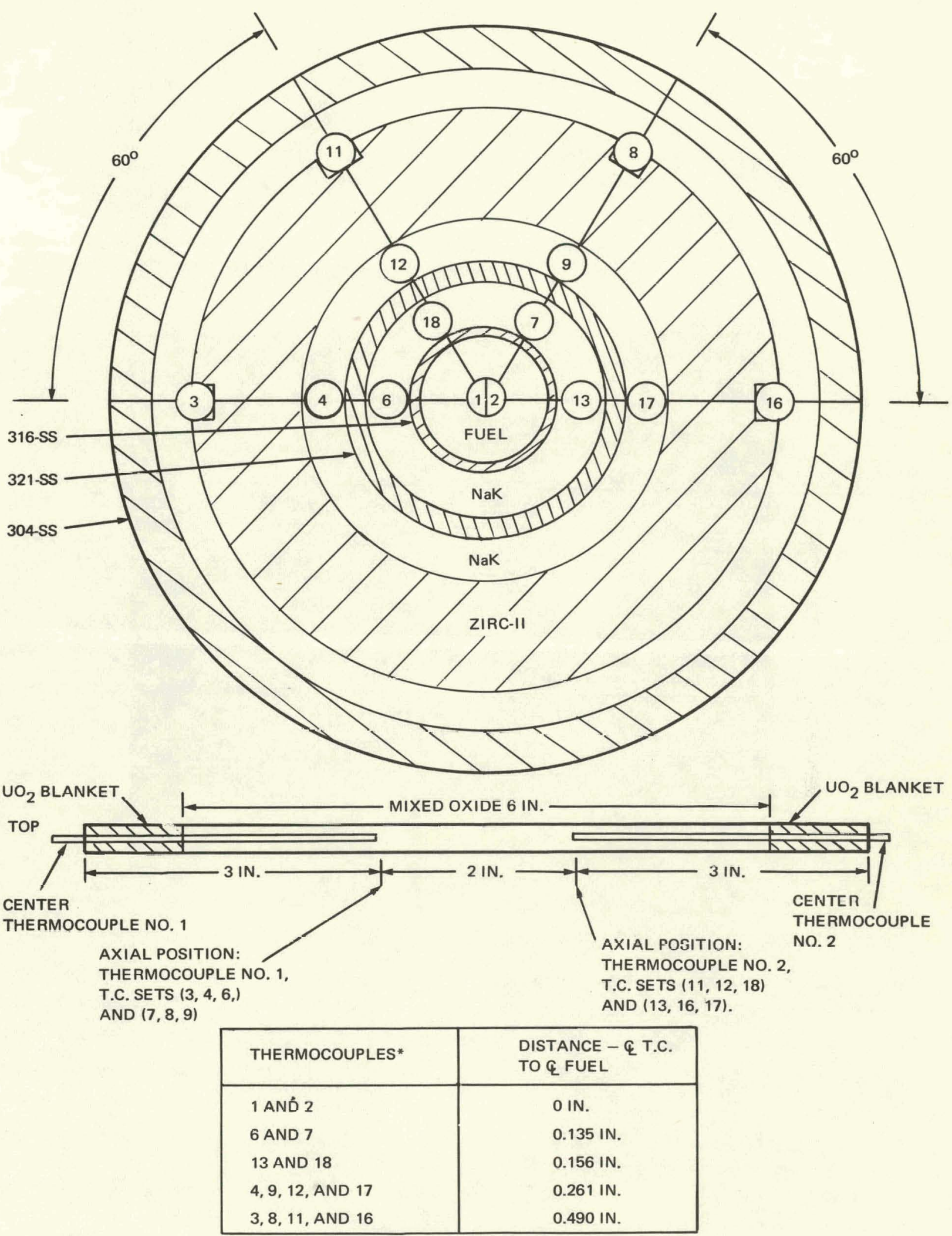

*THERMOCOUPLES NO. 1 AND NO. 2 ARE TUNGSTEN-RHENIUM THERMOELEMENTS, ALL OTHERS ARE CHROMEL-ALUMEL

Figure 3-3. Radial Cross-Section of Capsule E1AA 


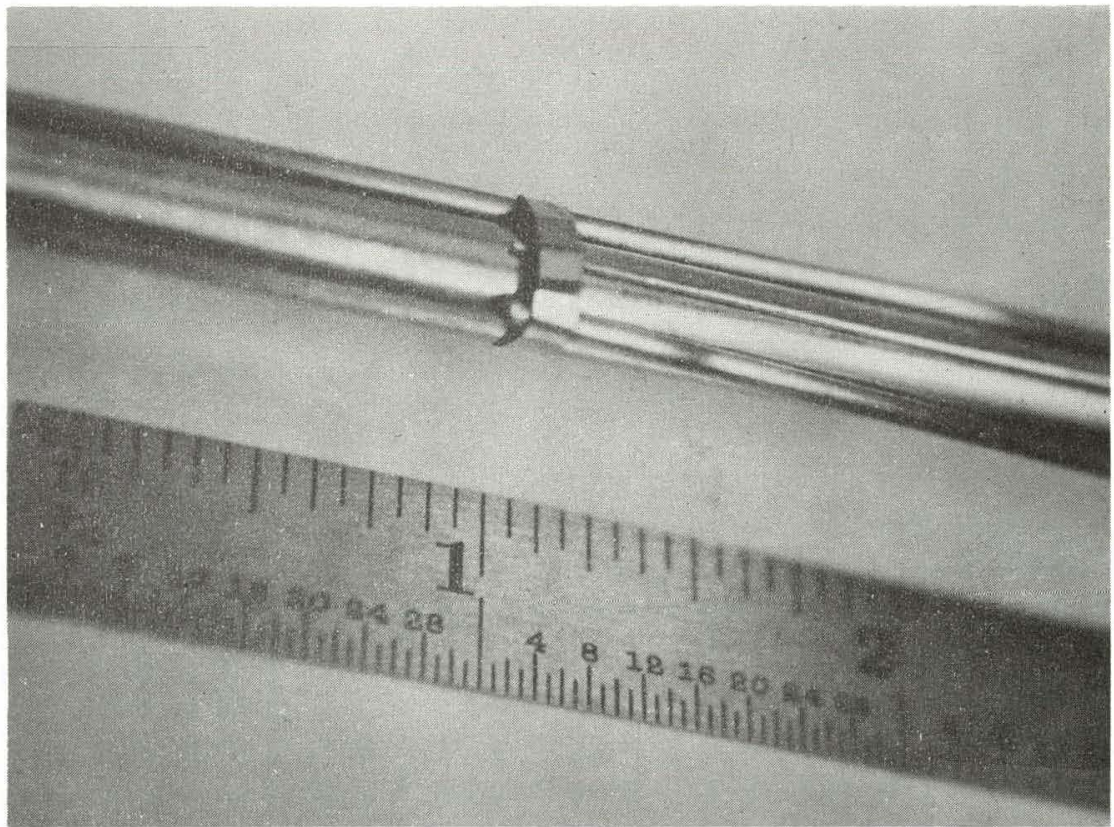

NEG. NO. 68PX0429

Figure 3-4. 1/16 Inch and 20 Mil o.d. Chromel-Alumel Thermocouples Around Fuel Pin Cladding 

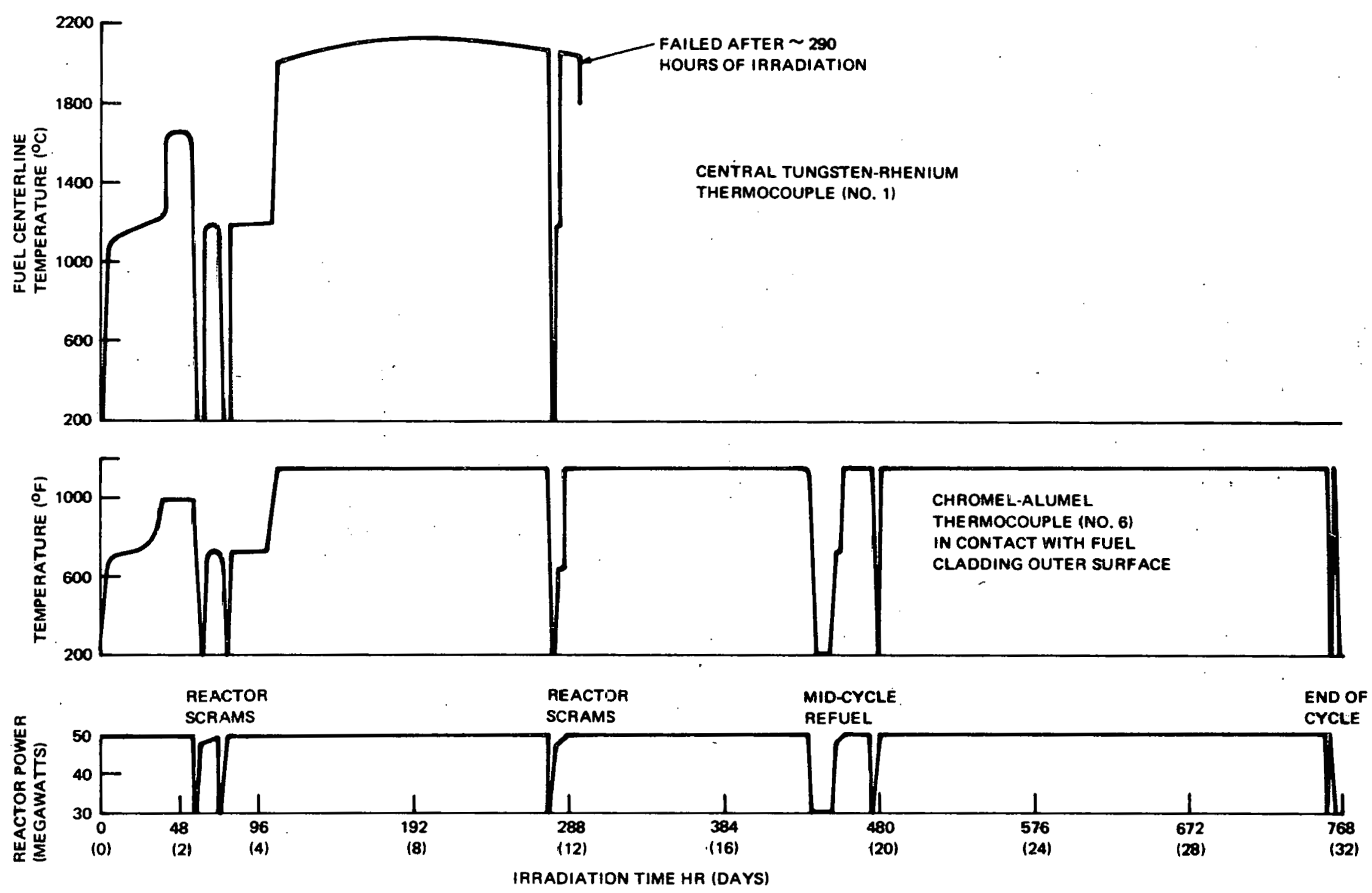
CHROME L-ALUMEL THERMOCOUPLE (NO. 6) IN CONTACT WITH THE FUEL CLADDING

OUTER SURFACE
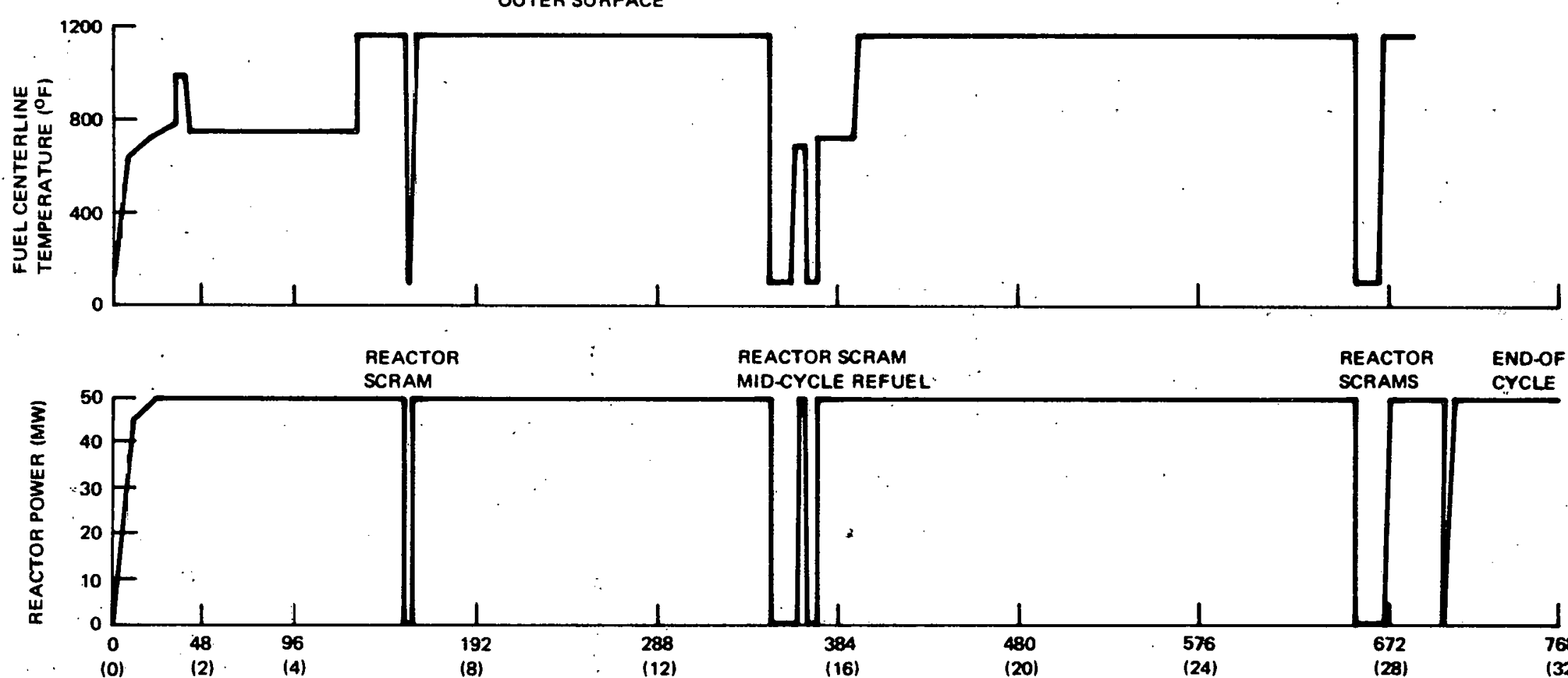

REACTOR

SCRAM

REACTOR SCRAM MIDCYCLE REFUEL

REACTOR SCRAMS

END-OF CYCLE
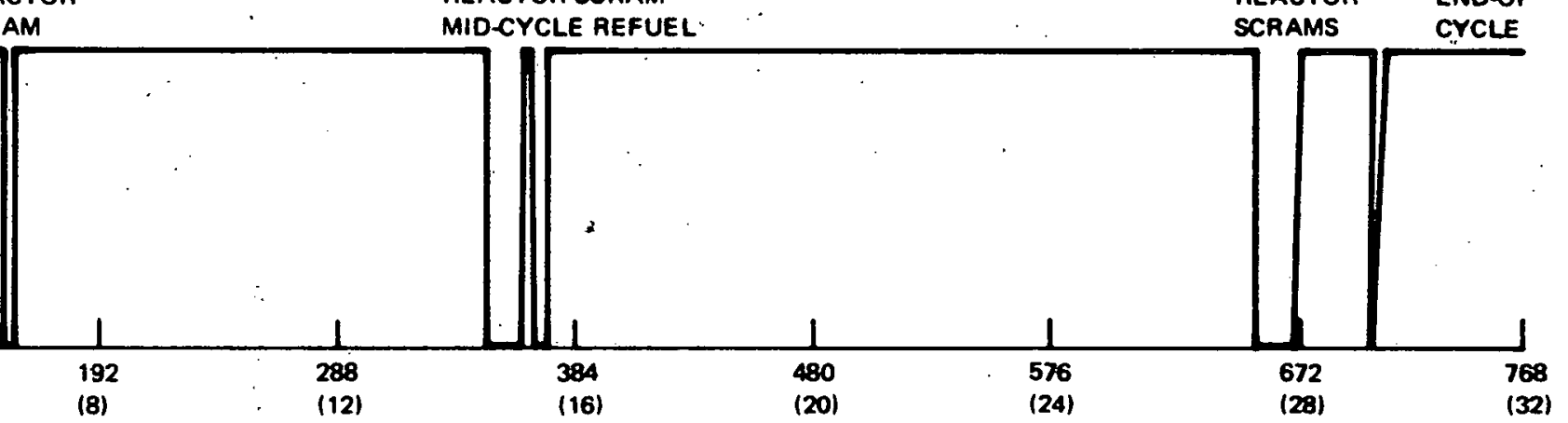

Figure 3-5b. Irradiation Historj of Capsule E1AA - GETR Cycle 98 
TABLE 3-1

FUEL PIN PARAMETERS

Fuel Type
O/M Range
Pellet Density (\% T.D.)
Smeared Density (\% T.D.)
w/\% PuO ${ }_{2}$ (\%)
Enrichment (\% U-235)
Pellet Diameter (Inches)
Diametral Gap (Mils)
Axial Gap (Mils)
Fuel Length (Inches)
Nominal Annulus Size (Mils)
Cladding Material
Cladding i.d. (Inches)
Cladding o.d. (Inches)

Annular Pellets
$1.97 \pm 0.015$
$91.4-93.3$
$80.00-82.48$
$19.4-20.28$
$9.9-10.62$
$0.2189 \cdot 0.2192$
$0.9-1.4$
0
5.978
$72 \cdot 74$
316 SS
$0.2201 \cdot 0.2203$
$0.2502-0.2509$

\section{TEST RESULTS}

\subsection{LINEAR POWER CALCULATIONS}

The majority of the thermocouples operated in a satisfactory manner throughout the irradiation. Only three of the thermocouples failed to perform properly. Thermocouples No. 2 and No. $7^{*}$ (a tungsten-rhenium and chromel-alumel thermocouple, respectively) did not respond during-the initial reactor startup. The other central tungsten-rhenlum thermocouple (No. 1) operated for approximately 290 hours.

A computer code was developed to aid in the analysis of the data. Linear powers were calculated from the thermocouple data using the following relationship:

$$
\int_{T_{1}}^{T_{2}} K d T=\frac{W}{2 \pi} \log _{e}\left(R_{1} / R_{2}\right)
$$

\footnotetext{
* Refer to Figure 3-3 for the location of the various thermocouples in the capsule.
}

$$
\begin{aligned}
& \text { Where } \quad K=\text { thermal conductivity as a function of } \\
& \text { temperature } \\
& T_{1}, T_{2}=\text { Temperatures at } R_{1} \text { and } R_{2} \\
& W=\text { linear power } \\
& R_{1}=\text { Radial distance from the center of the } \\
& \text { fuel to the center of the thermocouple } \\
& \text { reading } T_{1} \text {. } \\
& R_{3}=\text { Radial distance from the center of the } \\
& \text { fuel to the center of the thermocouple } \\
& \text { reading } T_{2} \text {. } \\
& R_{1}>R_{2}
\end{aligned}
$$

Integral conductivity curves for each of the materials in the capsule were determined trom the literature and are defined by polynomial equations (see Appendix $\mathrm{C}$ ). The program assumed that the temperature recorded by a thermocouple was that of the NaK coolant existing at the geometric center of the thermocouple on the assumption that there was no convection flow.

As an illustration of calculations used in the computer program, the following example shows the method for determining linear power from temperatures recorded by thermocouples 4 and 6 , (see Figure 4-1). 
REAP 13603

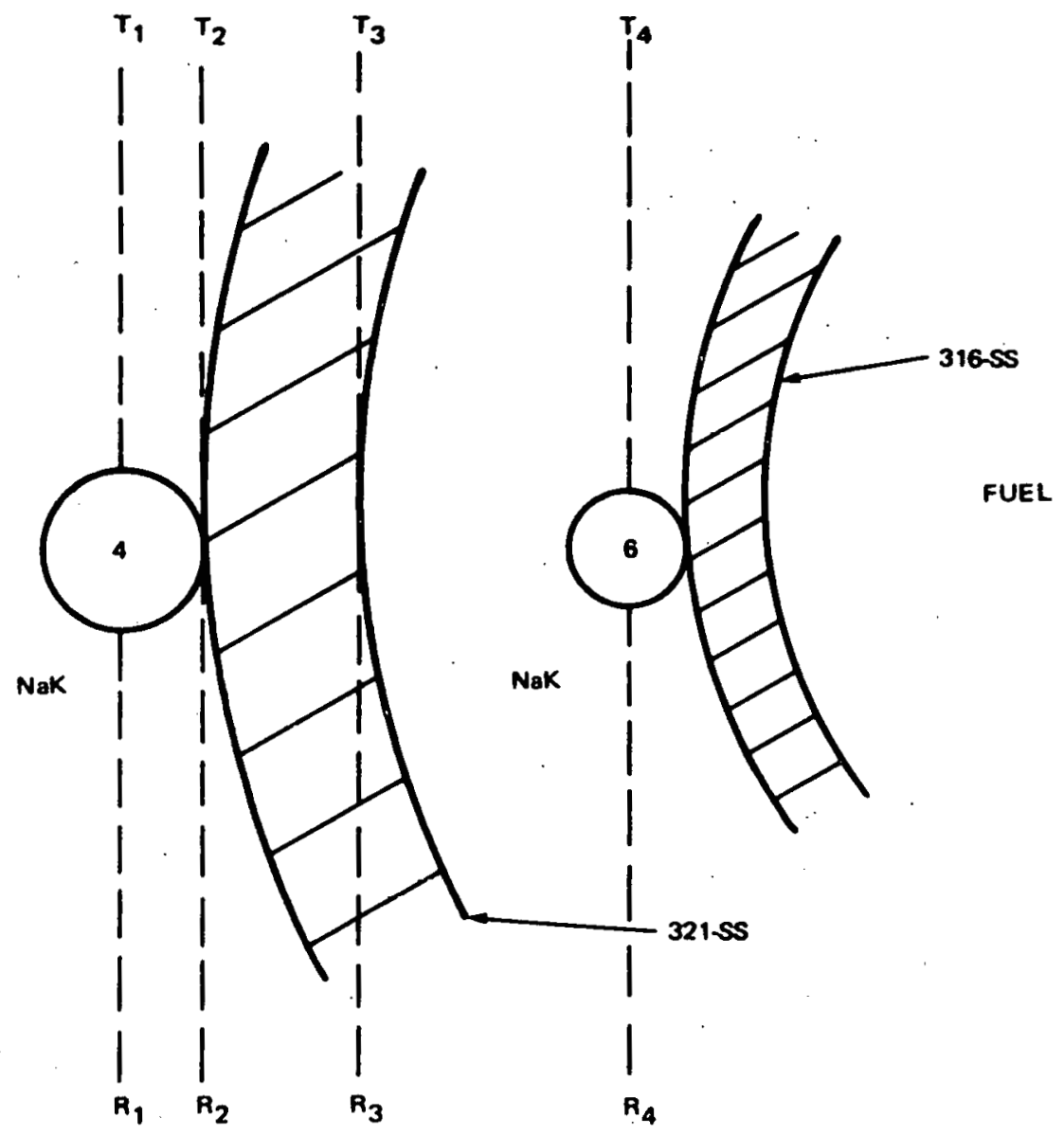

Figure 41. Interfaces between Thermocouples No. 4 and 6.

$-10-$ 


$$
\begin{aligned}
W_{4-6}=2 \pi \frac{\int_{T_{1}}^{T_{2}} K_{N a K} d T}{\ln \frac{r_{1}}{r_{2}}} \\
+2 \pi \frac{\int_{T_{2}}^{T_{3}} K_{321} s s d T}{\ln \frac{r_{2}}{r_{3}} d T} \\
+2 \pi \frac{\int_{T_{3}}^{T_{4}} \ln \frac{K_{N a K}}{r_{4}} d T}{\ln }
\end{aligned}
$$

The linear powers were determined through an iterative process. The iteration was initiated by assuming a power of $1 \mathrm{~kW} / \mathrm{ft}$ and calculating $T_{4}$ from the measured value of $T_{1}$ and comparing it to the actual value of $T_{4} .{ }^{*}$ Assumed power was then increased in increments of $1 \mathrm{~kW} / \mathrm{ft}, 0.1 \mathrm{~kW} / \mathrm{ft}$, and $0.01 \mathrm{~kW} / \mathrm{ft}$ until the calculated value for $T_{4}$ agreed with the measured value of $T_{4}$. Linear powers were calculated in this manner for all combinations of the three thermocouples in each "set" (see Section 3.2 for a definition of a "set"). The calculated values within a given thermocouple "set" generally agreed within $\pm 0.1 \mathrm{~kW} / \mathrm{ft}$. Comparison of the calculated linear power values for the various sets of thermocouples did not show any trend or bias in the data, and all of the data fell within $\pm 0.3 \mathrm{~kW} / \mathrm{ft}$ of their average value. These average values were used in analyzing the bulk of the experimental data.

Linear power values as a function of fuel center temperature were obtained by adjusting the radial position of the capsule in the reactor (vertical adjustments were made frequently during reactor operation to keep the capsule centered on the peak of the neutron flux). Radial adjustments were made during normal operation of the capsule or during start-up following a reactor scram.

Figure 4-2 illustrates the changes which occurred in the linear power-fuel center temperature relationship as a function of time. During the first $\mathbf{4 8}$ hours of capsule operation, the linear power appeared to be directly related

\footnotetext{
- A subroutine was included in the computer program to account for gamma heating. This is discussed in detail in Appendix D.
}

to fuel center temperatures between $1100^{\circ}$ and $1650^{\circ} \mathrm{C}$. Additional data obtained after 3 and 5 days of operation (50 to 96 hours), showed a change in this relationship at fuel center temperatures less than $1600^{\circ} \mathrm{C}$. The change indicated a decrease in the heat transfer capabilities of the fuel pin, so that for constant linear power operation the fuel center was approximately 80 to $100^{\circ} \mathrm{C}$ hotter. Data recorded at center temperatures between $1600^{\circ}$ and $2000^{\circ} \mathrm{C}$ appeared to be an extension of the linear relationship indicated during the first $\mathbf{4 8}$ hours of operation.

The lower curve in Figure 4-2 represents the center temperature-linear power relationship after nearly 270 hours of irradiation. Prior to this, the fuel pin operated at a constant linear power of $15 \mathrm{~kW} / \mathrm{ft}$ for nearly 150 hours. During this period, an anomaly in the fuel center temperature was observed. The central tungstenrhenium thermocouple indicated a gradual increase in temperature from the initial value of $2000^{\circ} \mathrm{C}$. A peak temperature of $2130^{\circ} \mathrm{C}$ was recorded, followed by a gradual decrease to $2055^{\circ} \mathrm{C}$. Figure 4-3 illustrates this occurrence. A similar case of fuel center temperature increasing from 2000 to $2100^{\circ} \mathrm{C}$ during constant power operation has previously been observed in $\mathrm{UO}_{2}{ }^{7}$ Following this constant power operation, the fuel pin was slowly cycled between 7 and $15 \mathrm{~kW} / \mathrm{ft}$. The data indicated a decrease in the heat transfer capability of the fuel pin. Refer again to the lower curve in Figure 4-2. For all linear powers, the fuel center temperature was almost $200^{\circ} \mathrm{C}$ higher than those measured during the start of irradiation.

The reactor experienced its third scram after 278 hours of irradiation. Shortly after coming back to power, the center $W$-Re thermocouple failed.

\subsection{FUEL CLAD SURFACE TEMPERATURES}

The outside surface temperature of the clad was determined from the temperature of the thermocouples strapped to the clad. This could be done if uniform heat dissipation from the fuel was assumed. It was determined that the clad surface temperature was considerably higher than the temperature of the thermocouples strapped to it. For the case of a 1/16-inch thermocouple, the clad surface could be as much as $125^{\circ} \mathrm{F}$ higher than the thermocouple when it was reading $1100^{\circ} \mathrm{F}$. A mure complete discussion of the determination of clad surface temperature may be found in Appendix E.

It was also noted that a temperature gradient existed around the circumference of the cladding with the hottest side facing the core. At peak operating temperature, the range was as great as 50 to $60^{\circ} \mathrm{F}$. This observation was consistent throughout the life of the capsule. 


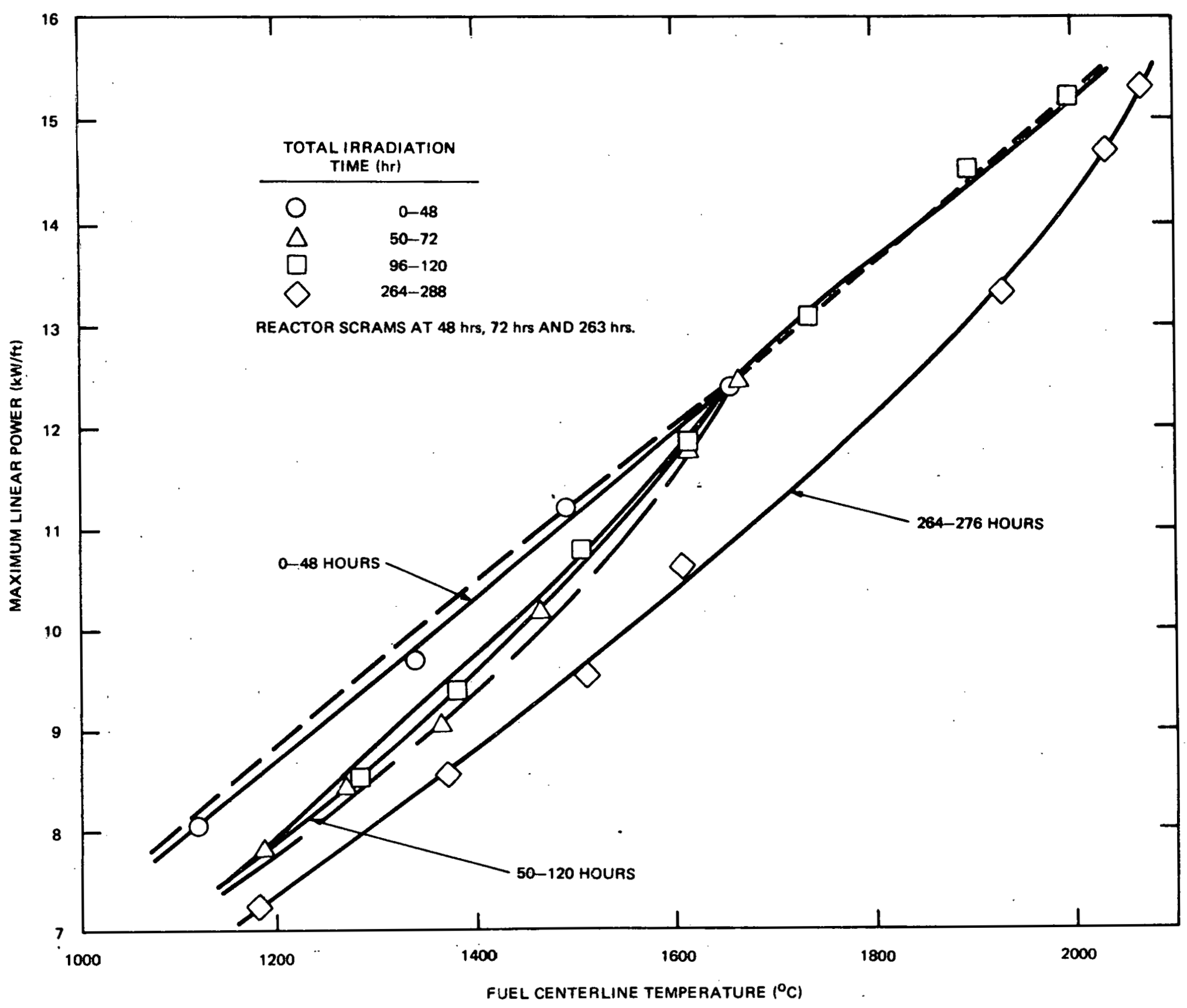

离

Figure 4-2. Linear Power Versus Fuel Temperature (Center) and Time 


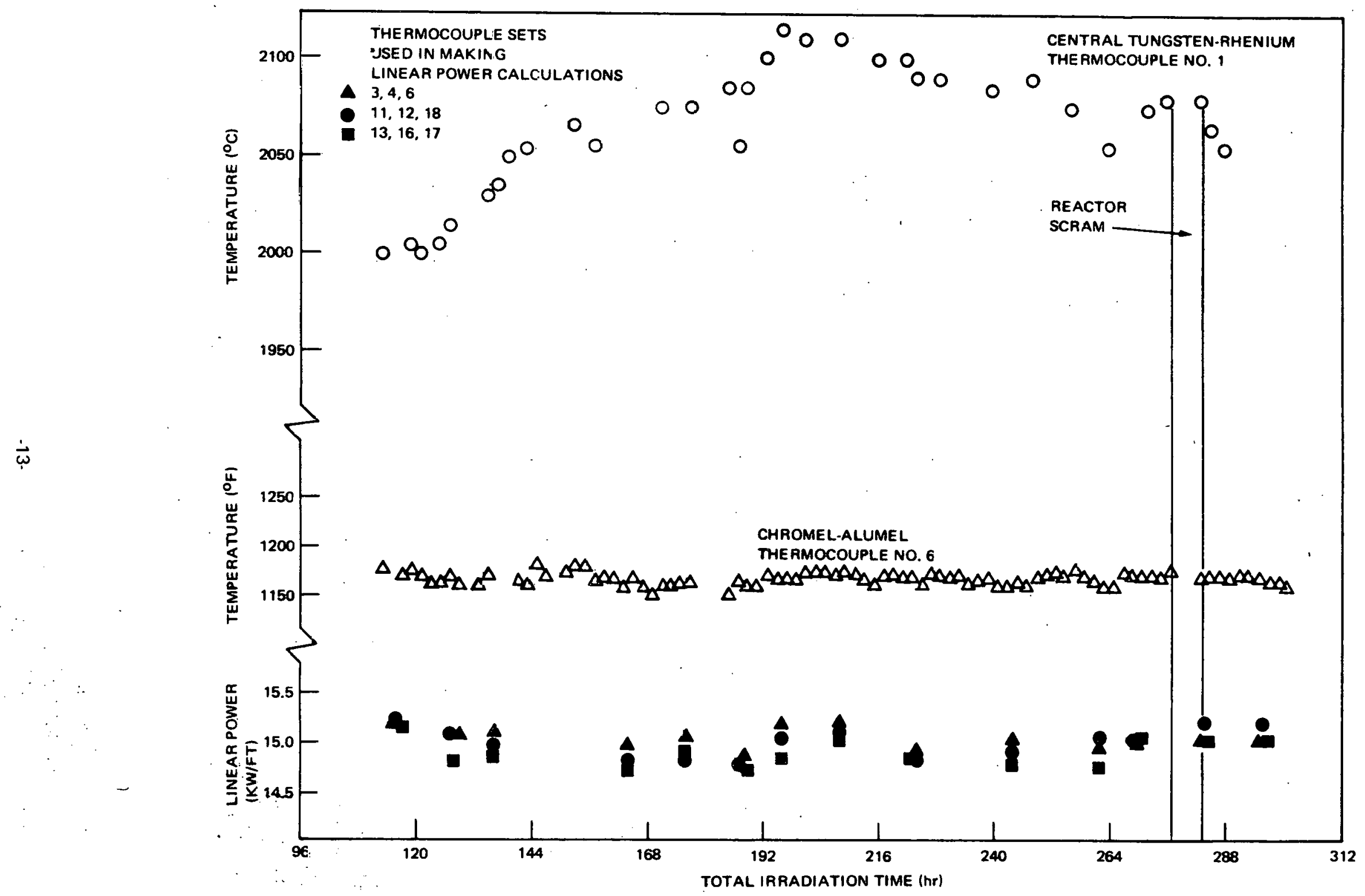

Figure 43. Increase in Fuel Center Temperature During Constant Linear Power Operation 


\subsection{FUEL INTEGRAL CONDUCTIVITY AND FUEL- CLADDING GAP COEFFICIENTS}

The experiment design allowed reasonably accurate values of linear power and fuel cladding surface temperatures to be calculated. These parameters were utilized to evaluate the fuel integral conductivity, as defined in the following equation:

$$
\int_{T_{S}}^{T} G\left(K d T=\frac{W}{4 \pi}\right. \text { (PSF) }
$$

Where

$$
\begin{aligned}
K & =\text { fuel thermal conductivity }\left(\mathrm{w} / \mathrm{cm}^{\circ} \mathrm{C}\right) \\
{ }^{T} \mathrm{C} & =\text { fuel center temperature }\left({ }^{\circ} \mathrm{C}\right) \\
T_{S} & =\text { fuel surface temperature }\left({ }^{\circ} \mathrm{C}\right) \\
W & =\text { linear power }(\mathrm{w} / \mathrm{cm}) \\
\text { PSF } & =\text { power shape factor }{ }^{*}=0.522
\end{aligned}
$$

The fuel center temperature was measured directly with the tungsten-rhenium thermocouple. The fuel surface temperature was calculated through the interrelationship of fuel cladding outside surface temperature, corresponding linear power, thermal conductivity of the cladding material, and the fuel-cladding gap coefficient. The latter term is defined as the fuel surface heat flux divided by the difference between fuel surface and cladding inside diameter temperatures. Thus,

$H=\frac{Q / L}{\pi D_{F}} \times \frac{1}{T_{s}-T_{c_{I . D}}}$

Where

$$
\begin{aligned}
H & =\text { fuel-cladding gap coefficient }\left(\mathrm{Btu} / \mathrm{hr} \mathrm{ft}^{2 \circ} \mathrm{F}\right) \\
\mathrm{Q} / \mathrm{L} & =\text { linear power }(\mathrm{Btu} / \mathrm{hr} \mathrm{ft}) \\
\mathrm{DF} & =\text { fuel outside diameter }(\mathrm{ft}) \\
\mathrm{T}_{\mathrm{S}} & =\text { fuel surface temperature }\left({ }^{\circ} \mathrm{F}\right) \\
\mathrm{T}_{\mathrm{C}_{1 . D}} & =\text { cladding inside diameter temperature }\left({ }^{\circ} \mathrm{F}\right)
\end{aligned}
$$

Gap conductivity is a difficult parameter to characterize since it is a complex function of temperature, burn- up, initial fuel-cladding gap size, fuel density, cladding thermal expansion characteristics, and the gas within the gap. For this experiment, it was decided to calculate fuel surface temperatures and determine gap coefficient values

* This unitless factor is related to the isotopic composition of the fuel and its neutron absorption cross-sections. The power shape factor for EIAA was calculated to be 0.522 . This calculation is shown in Appendix $F$. by assuming a fuel integral curve and using Equation 4-4. The base integral curve utilized was that suggested by Baily, et al., 5 and accounts for densification changes, Figure 4-4. Density corrections to 97 and 99\% T.D. were used at temperatures of $1500^{\circ}$ and $2000^{\circ} \mathrm{C}$, respectively. Nominal linear power values were used along with average temperatures of the cladding outer surface determined by the three monitoring surface thermocouples. The results of the calculations produced a curve showing a variation of gap coefficient with fuel center temperature, Figure 4-5. Also plotted on the figure are data generated in an earlier thermal conductivity experiment, capsule EIA. ${ }^{4}$ When it is considered that E1A had a larger initial fuel-clad gap than E1AA and argon back-fill gas instead of helium, the agreement is reasonable. The curve in Figure 4.5 for E1AA represents gap conductivity during initial irradiation. This curve was used to make subsequent calculations of fuel surface temperature. The assumption that any change in gap conductivity during irradiation of the capsule was insignificant, was supported by previous results. ${ }^{5,6}$

In equation 4-3 the fuel center temperature (TCl), linear power (W), and the power shape factor (PSF) were readily determined. By developing a relation for gap conductivity vs. center temperature, fuel surface temperatures (TS) could be calculated to correlate the information necessary to bulld a curve for fuel integral conductivity. Calculated integral values were projected from a point on the base curve, Figure 4-4, which represented the fuel surface ternperature to the corresponding fuel center temperature. The results of this evaluation are shown in Figure 4-6. The fuel integral conductivity curve decreased after 2 days of reactor operation. Integral values were similar to that of the base curve at fuel center temperatures greater than $1600^{\circ} \mathrm{C}$. After a total irradiation of 270 hours (the last $\mathbf{1 5 0}$ hours at constant power of $15 \mathrm{~kW} / \mathrm{ft}$ ), an overall decrease in integral conductivity was evident.

\subsection{POST-IRRADIATION EXAMINATION}

On completion of irradiation testing, the capsule was transferred to the Radioactive Materials Laboratory (RML) for destructive examination A gross gamma scan of the capsule, Figure 4-7, indicated no abnormalties and that the fuel pin was intact. A puncture was made in the capsule body to check the activity of the contained gas. No evidence of fission gas release from the fuel pin was found.

The capsule was disassembled and the fuel pin was intact. Visual examination showed that the thermocouples had remained strapped to the cladding. An oblique view of the fuel pin shows a thermocouple to be in intimate contact with the cladding, Figure 4-8. 


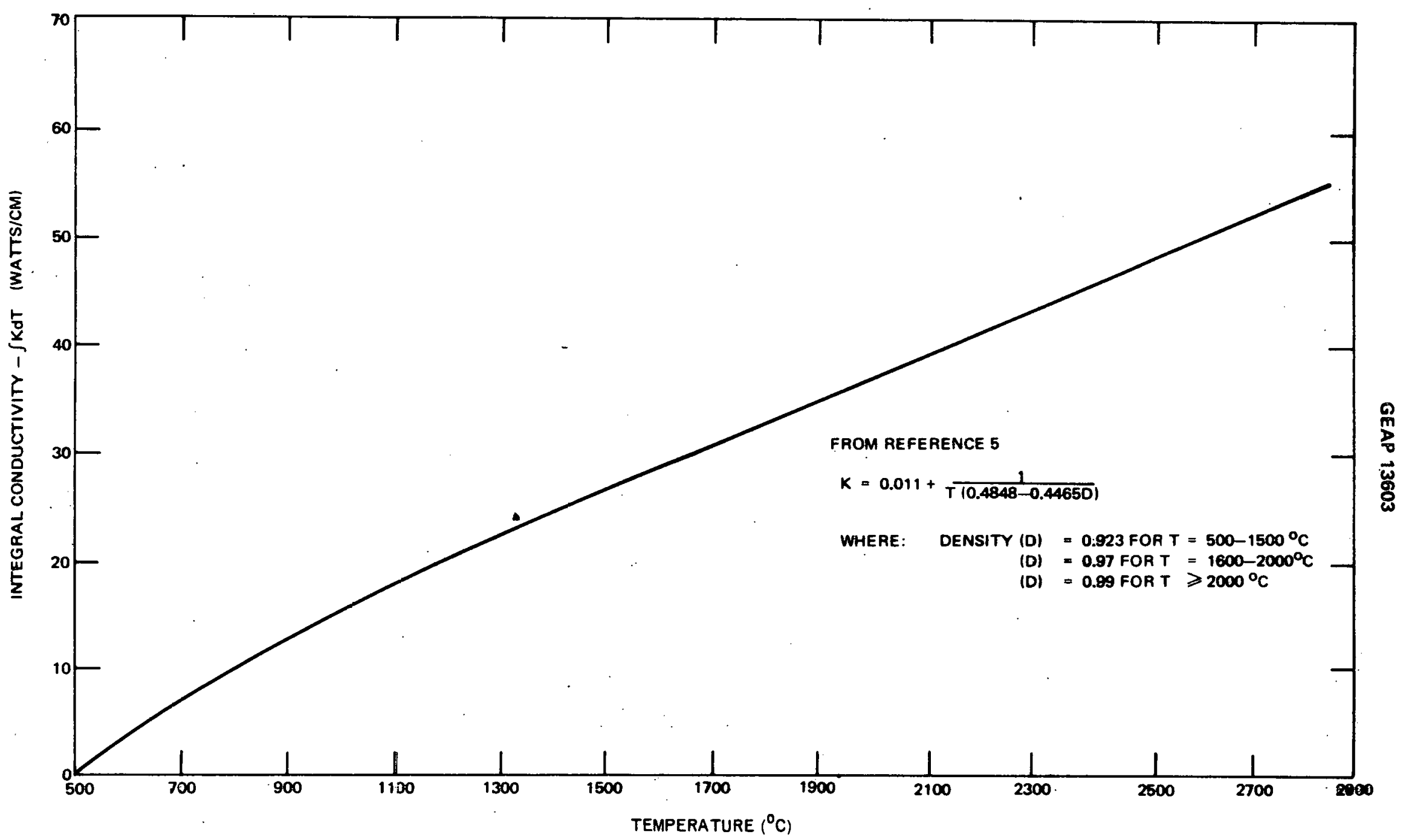

Figure 4-4. Integral Conductivity Cure $\left(\mathrm{Pu}_{0.2} \mathrm{u}_{0.8}\right) \mathrm{O}_{2.00}$ Above $500^{\circ} \mathrm{C}$ 


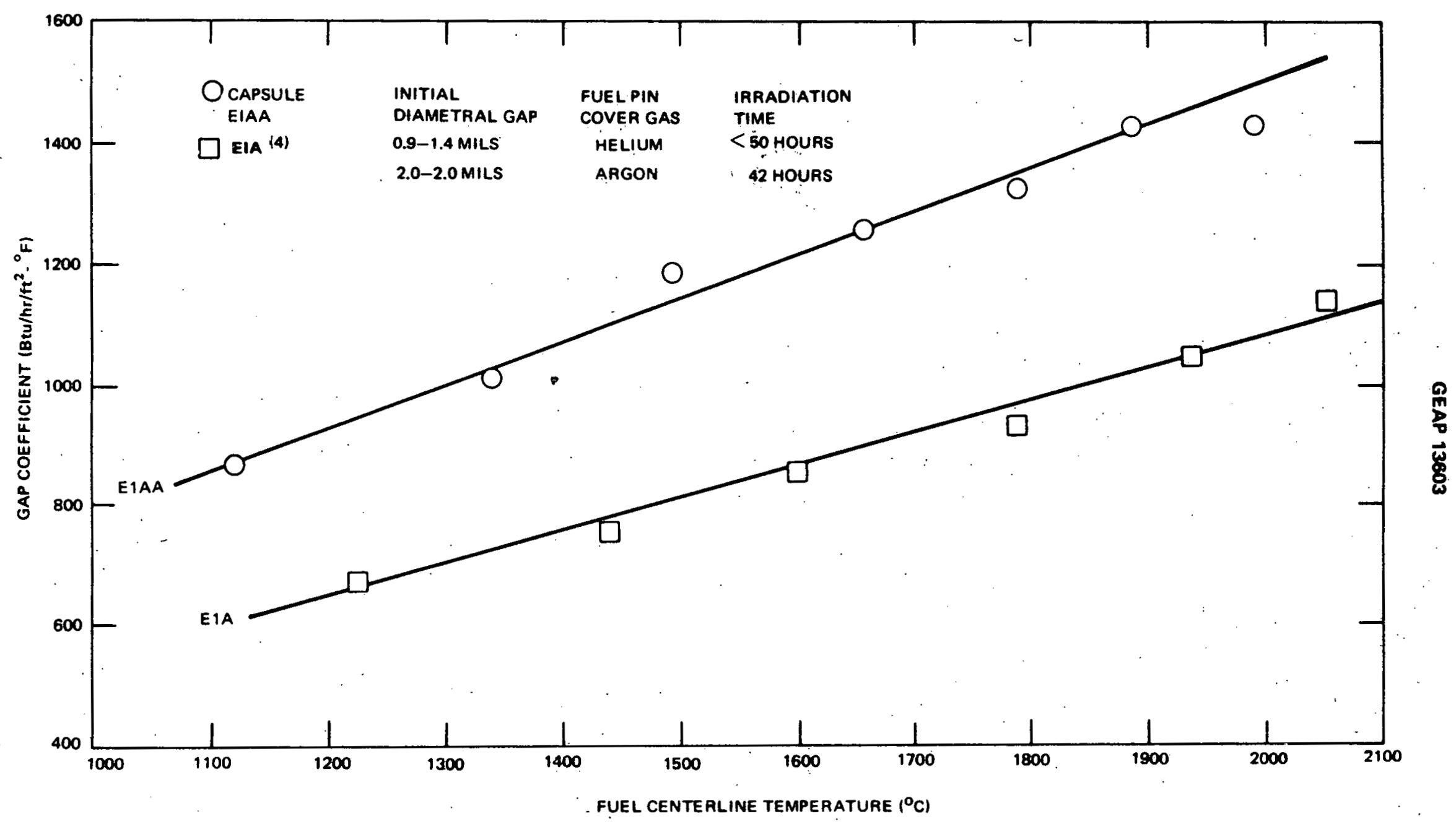




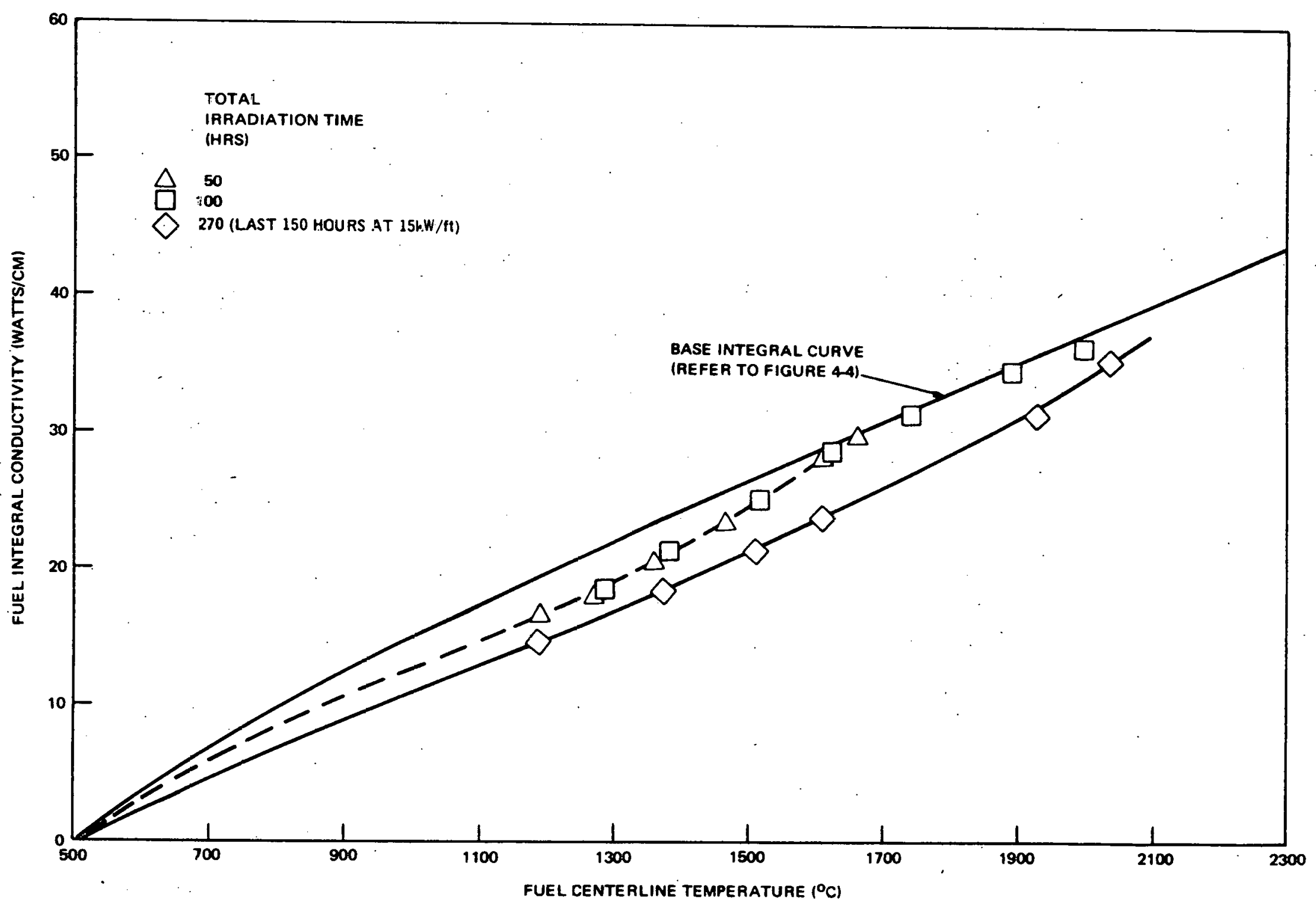




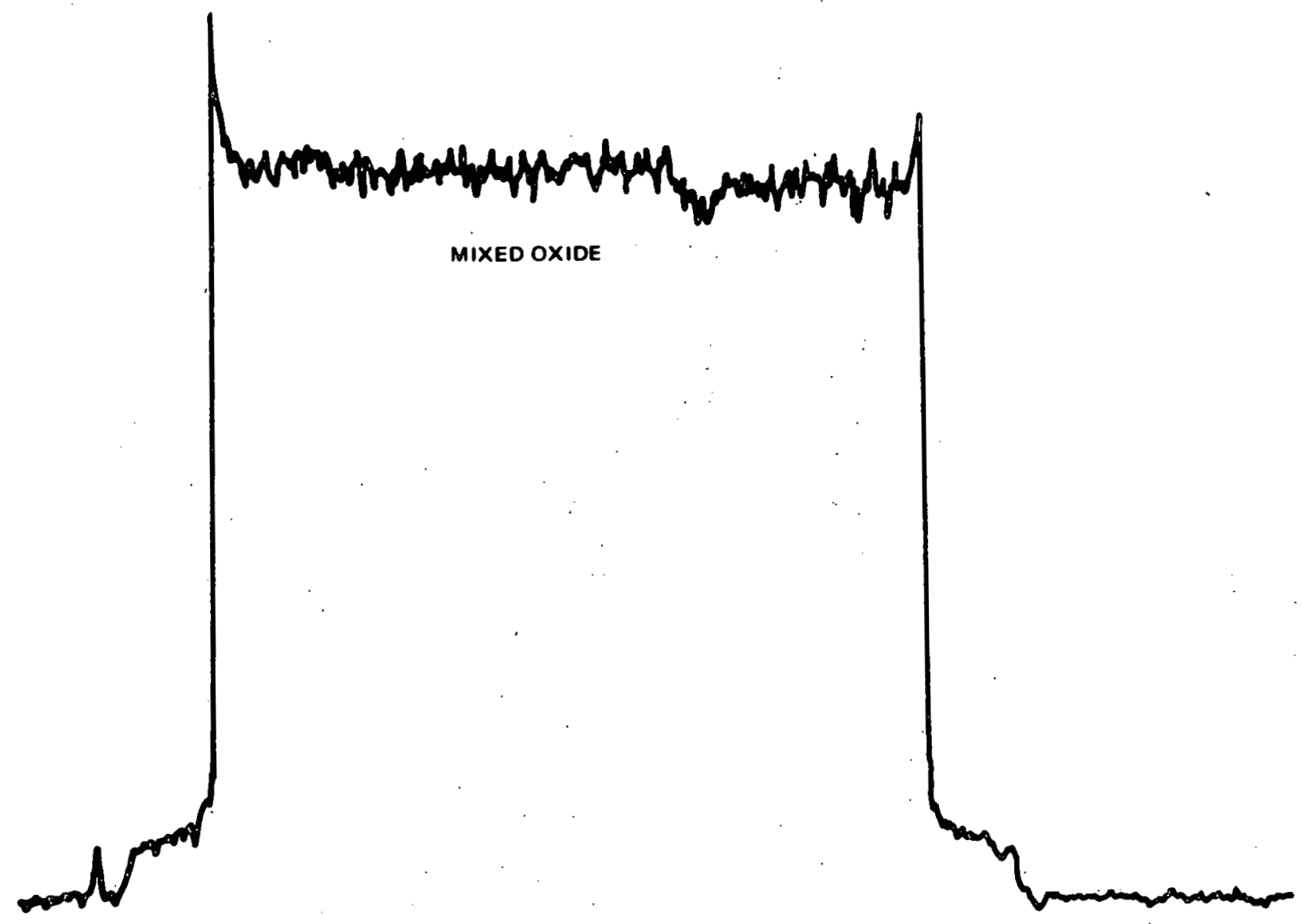

Figure 4-7. Capsule E1AA Gross Gamma Scan 


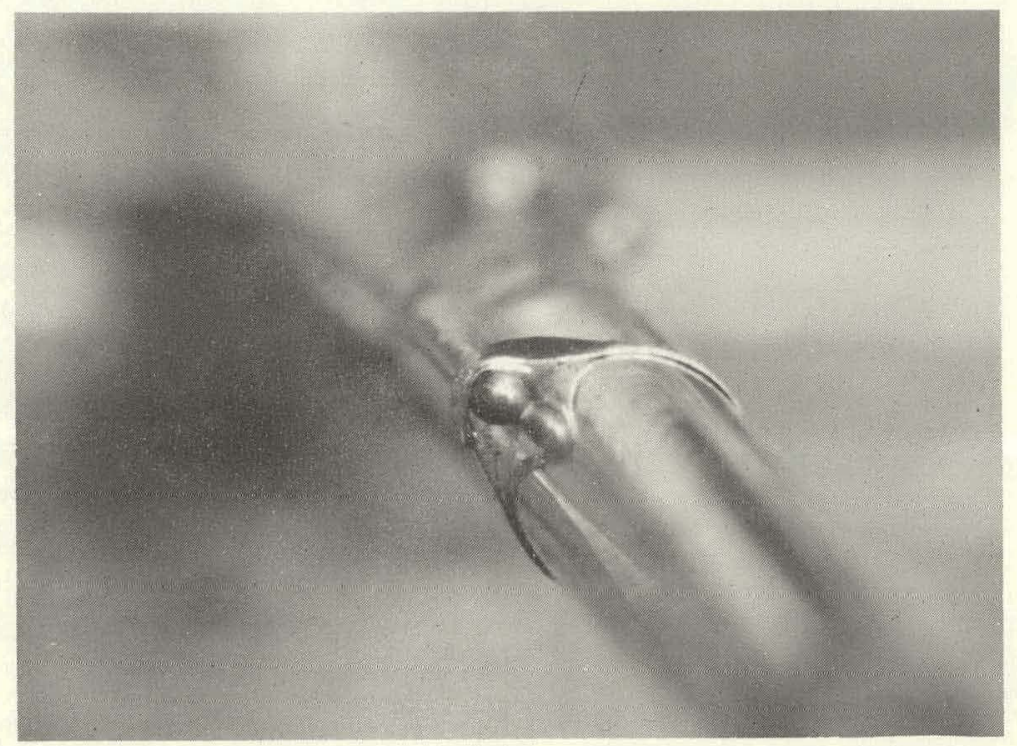

NEG NO. 43837

Figure 4-8. Post-Irradiation Contact of Chromel-Alumel Thermocouple (No. 18) with Fuel Pin Cladding 
After visual inspection, the thermocouples around the cladding were removed and profilometer traces made of the fuel pin. Diameter comparison with pre-irradiation diameter measurements indicated that there was no cladding strain that could be related to the fuel-cladding interaction or any other type of irradiation induced swelling.

The fuel pin was punctured and a fission gas analysis performed. The gas constituents analyzed are listed in Table 4-1. Assuming a gas yield of 0.32 atoms/fission and the number of fissions to be $3.75 \times 10^{20}$ fission/cc, a fission gas release value of $14.5 \%$ was calculated. This value is consistent with the relatively low center line temperature of the fuel.

TABLE 4-1

\section{FISSION GAS ANALYSIS}

Bomb Pressure
Volume of Gas
$\mathrm{O}_{2}$
$\mathrm{~N}_{2}$
$\mathrm{H}_{2}$
$\mathrm{CO}$
$\mathrm{CO}_{2}$
$\mathrm{CH}_{4}$
$\mathrm{X}_{\mathrm{e}}$
$\mathrm{K}_{\mathrm{r}}$
$\mathrm{Ar}$
$\mathrm{H}_{\mathrm{e}}$
Gamma scan $\left(\mathrm{K}_{\mathrm{r}}-85\right)$

1.34 Torr

$2.3 \mathrm{cc}$

$2.36 \pm 0.03 \%$

$11.9 \pm 0.06 \%$

Not detected

Not detected

Not detected

Trace $(<0.02 \%)$

$80.1 \pm 0.8 \%$

$6.31 \pm 0.02 \%$

$0.39 \pm 0.01 \%$

$1.7 \pm 0.2 \%$

$1.35 \times 10^{17}$ atoms/cc

$1.38 \times 10^{17}$ atoms/cc

\subsection{METALLOGRAPHY}

Various regions of fuel pin E1AA were sectioned and visually examined, Figure 4-9. No unusual observations and no reaction between the fuel and clad or thermocouple sheath were noted.

Autoradiographs were taken of select metallographic sections $B, D$, and $F$ to determine the distribution of alpha and beta-gamma activity. The autoradiographs are shown in Figure 4-10. As illustrated, there was no significant variation in alpha activity. A high degree of beta-gamma activity was observed near the fuel-cladding interface in Section B. This was attributed to beta-gamma shine coming from a hole left by a fuel particle falling out during sample preparation. The columnar grain region was less active than the outer periphery of the fuel.
Diametral composites of Sections $D$ and $C$ are shown in Figure 4-11. The cross-sections representing the two horizontal planes at the ends of the tungsten-rhenium thermocouples were similar in appearance suggesting that the two thermocouple planes operated at the same power. The region in which columnar grain growth formation commenced, varied between 0.066 to 0.076 inch from the center of the pin in both cases 10.030 to 0.040 inch from the rim of the annulus). The fuel-cladding gap appeared to have closed from the initial value of 1-1.5 mil to approximately 0.5 mil.

The metallographic appearance of Section $F$, taken from the upper end of the fuel pin, was similar to that of the two center sections $B$ and D. The extent of columnar grain growth formation, 0.070 to 0.075 inches from the pin center further suggests that this region of the fuel pin operated at about the same power as the two center sections. Of particular interest in this section was the closing of the center annulus from a pre-irradiation diameter of 0.074 inches to approximately 0.067 inches, Figure 4-12. This observation suggested that some axial fuel redistribution within the center annulus had occurred. It may be postulated that the combination of the decreasing center annulus due to axial fuel movement and thermal cycling of the fuel, could induce significant stresses on the center thermocouple sheath and ultimately result in thermocouple failure. No observation of thermocouple sheath deformation in the upper region of the fuel pin was noted in this investigation, but has been reported in other similarly designed experiments. ${ }^{7}$

No significant reaction was observed between the W26Re thermocouple sheath and the mixed oxide fuel or the beryllia insulation (refer to Figures 4-11 and 4-12). At least one thermoelement in each of these sections showed no effects of exposure. The appearance of the remaining thermoelements varied. No conclusive explanation is available for these varied appearances. They have been observed in previous experiments, however, and have been attributed to oxygen from the fuel, thermocouple cover gas, and from outgassing products. ${ }^{8}$

Localized fuel-cladding reactions, as shown in Figure 4-13, were observed around the cladding. The reactions penetrated to depths of $\sim 1 / 2$ mil. Of interest in Figure $4-13$, is the metallic appearing stringer extending from the cladding into the fuel to a depth of 3 mils. It is not clear whether the stringer is metal transported from the cladding, or metallic fission products contacting the cladding. A typical appearance of the cladding in the etched condition is illustrated in Figure 4-14. The clad was sensitized throughout, except for a 2 to $3 \mathrm{mil}$ band on the outer periphery. 


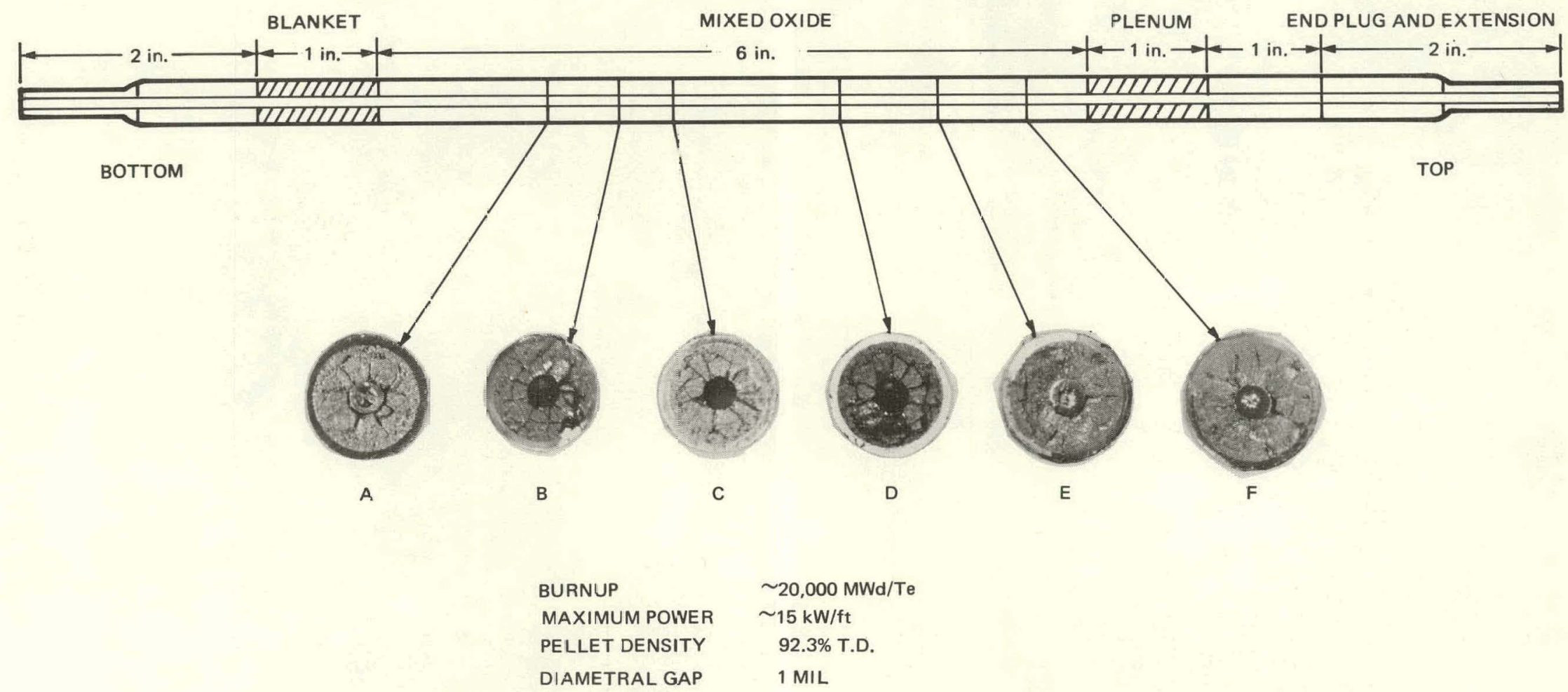

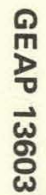

Figure 49. Fuel Pin E1AA Sectioning Diagram 


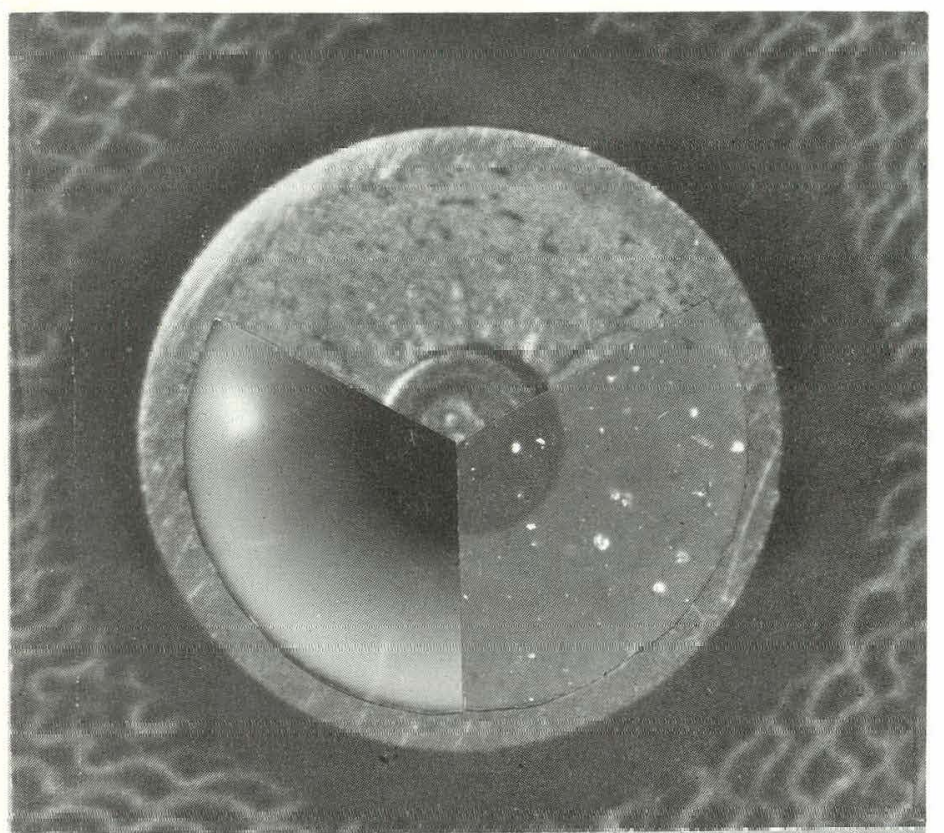

NEG. NO. A227-01, 02, 03

SECTION B*

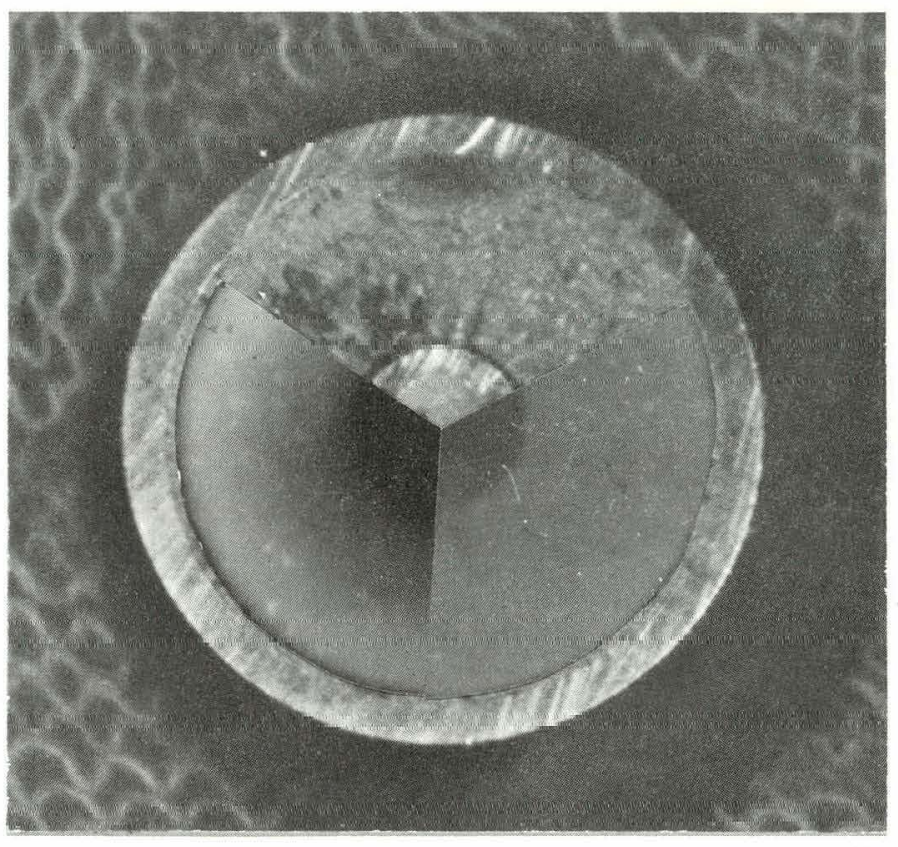

$10 \mathrm{X}$ NEG. NO. A228-01

SECTION "D"*

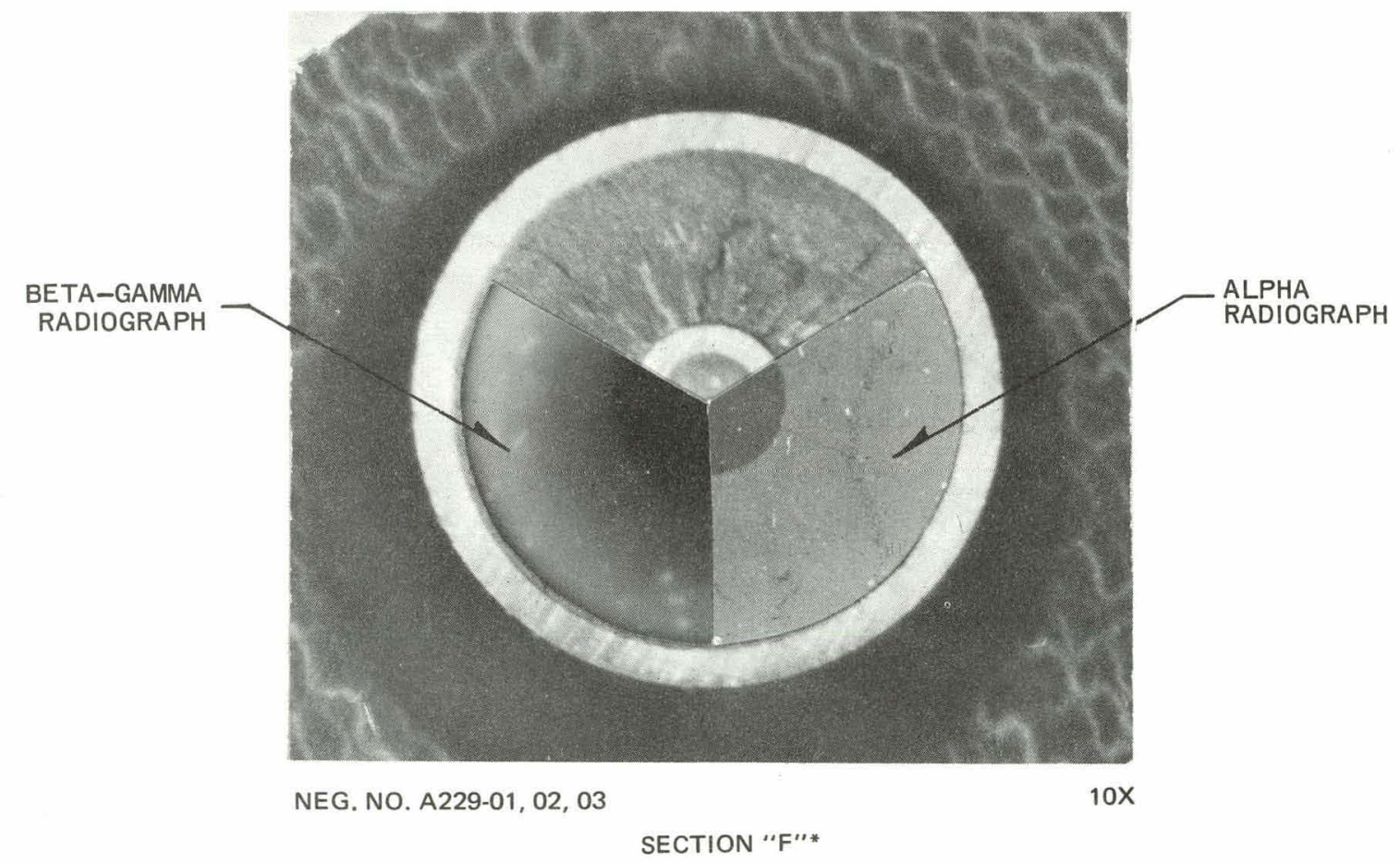

*SEE FIGURE 4-9 FOR LOCATION

Figure 4-10. Autoradiographs of E1AA Fuel Pin 


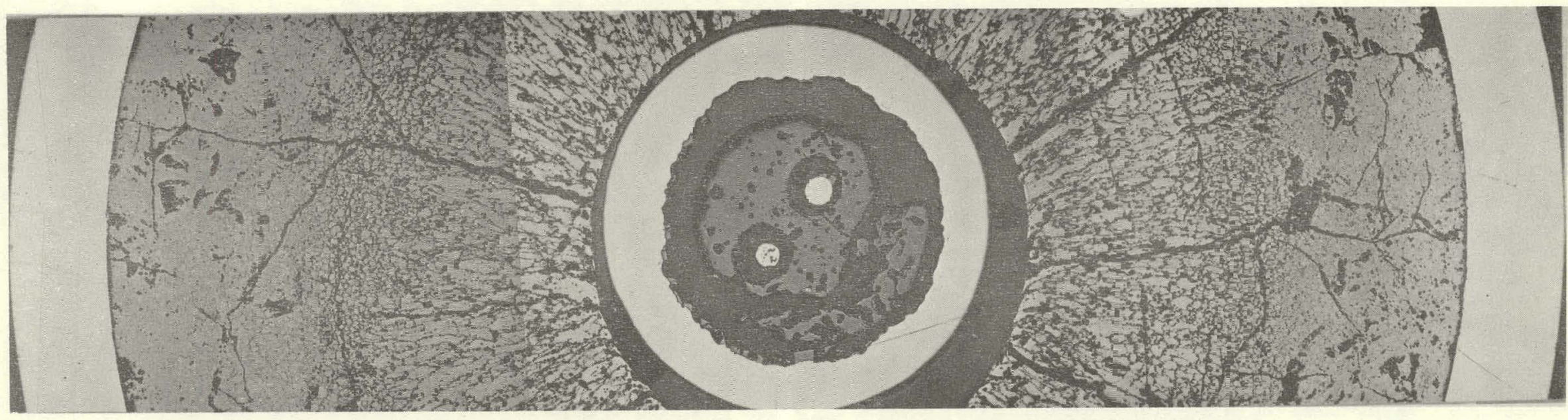

NEG. NO. A227-04, 05, 06

SEC-ICN "C"

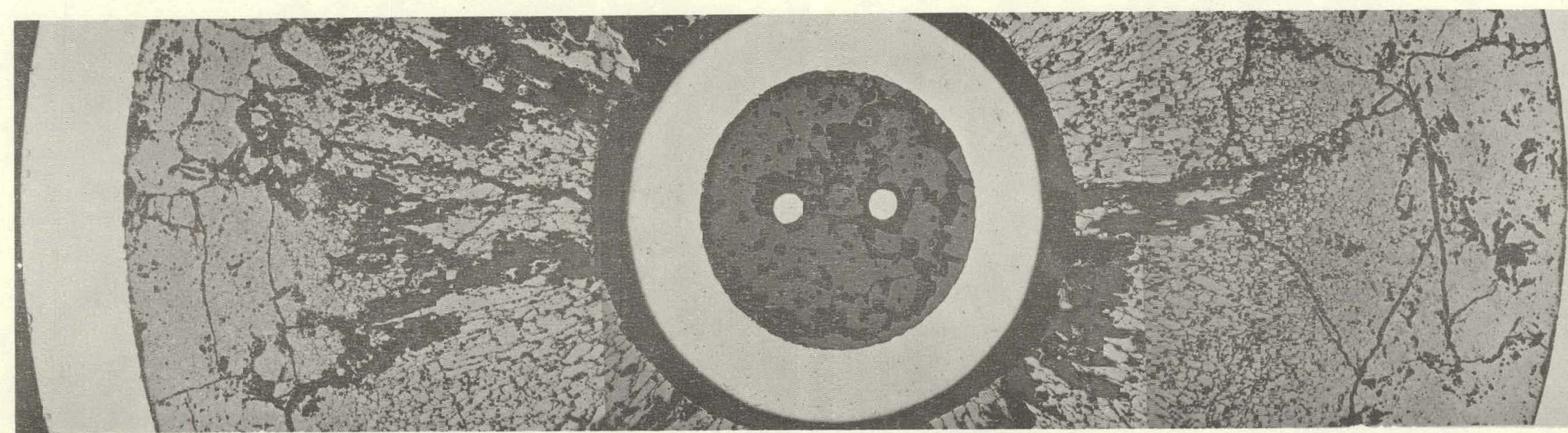

SECTION "D" 


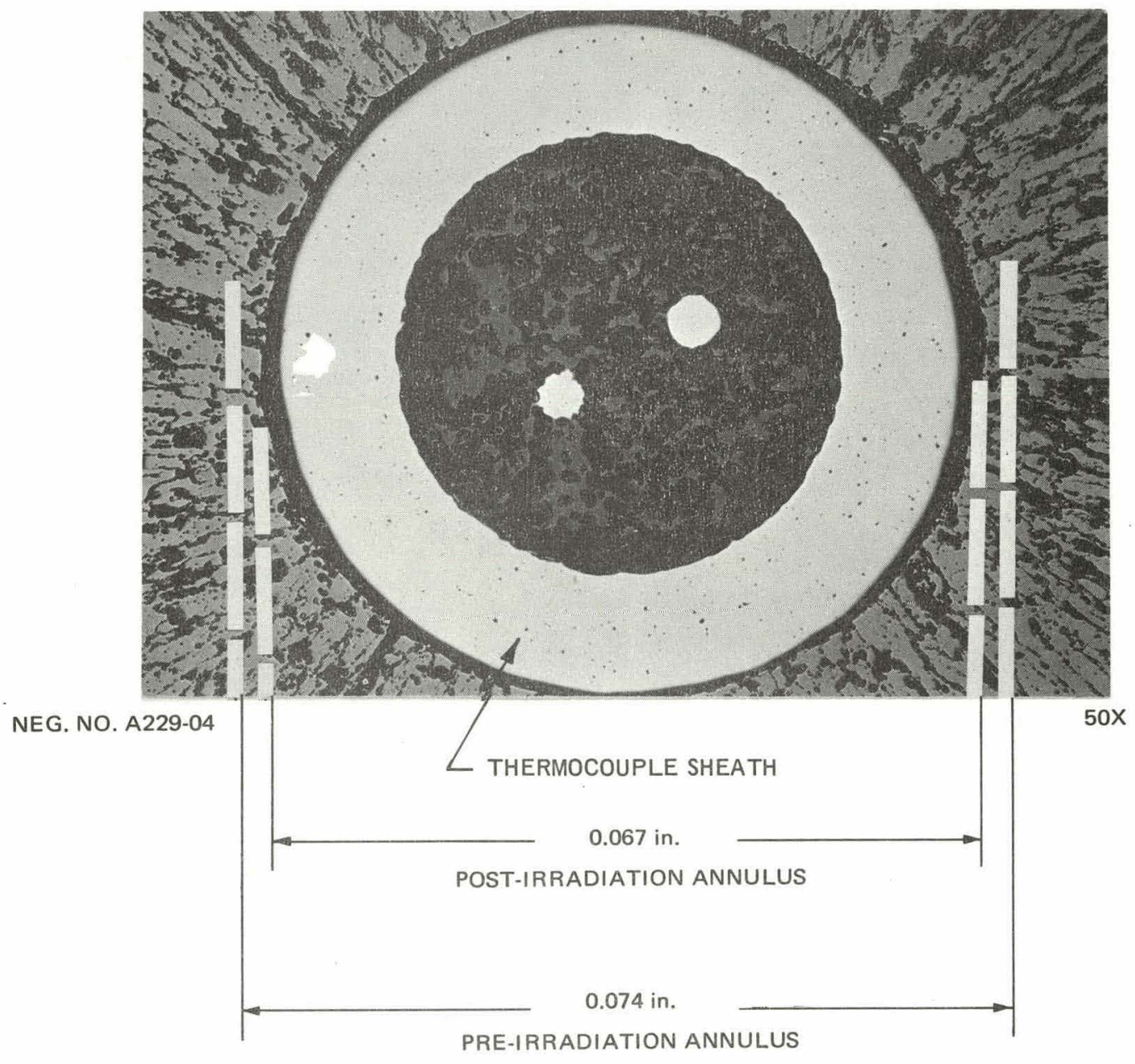

Figure 4-12. Post-Irradiation Fuel Annulus of Section "F" 


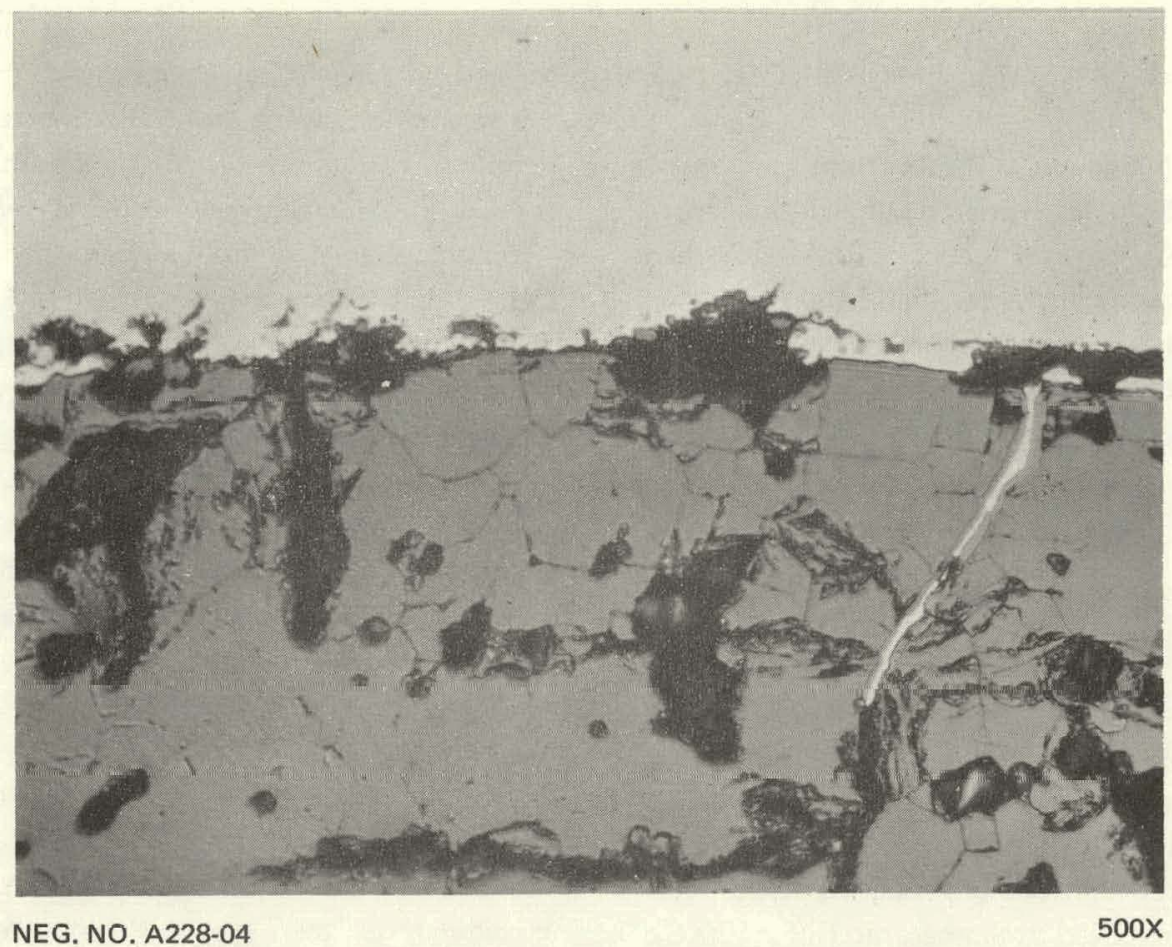

Figure 4-13. Fuel Cladding Interaction

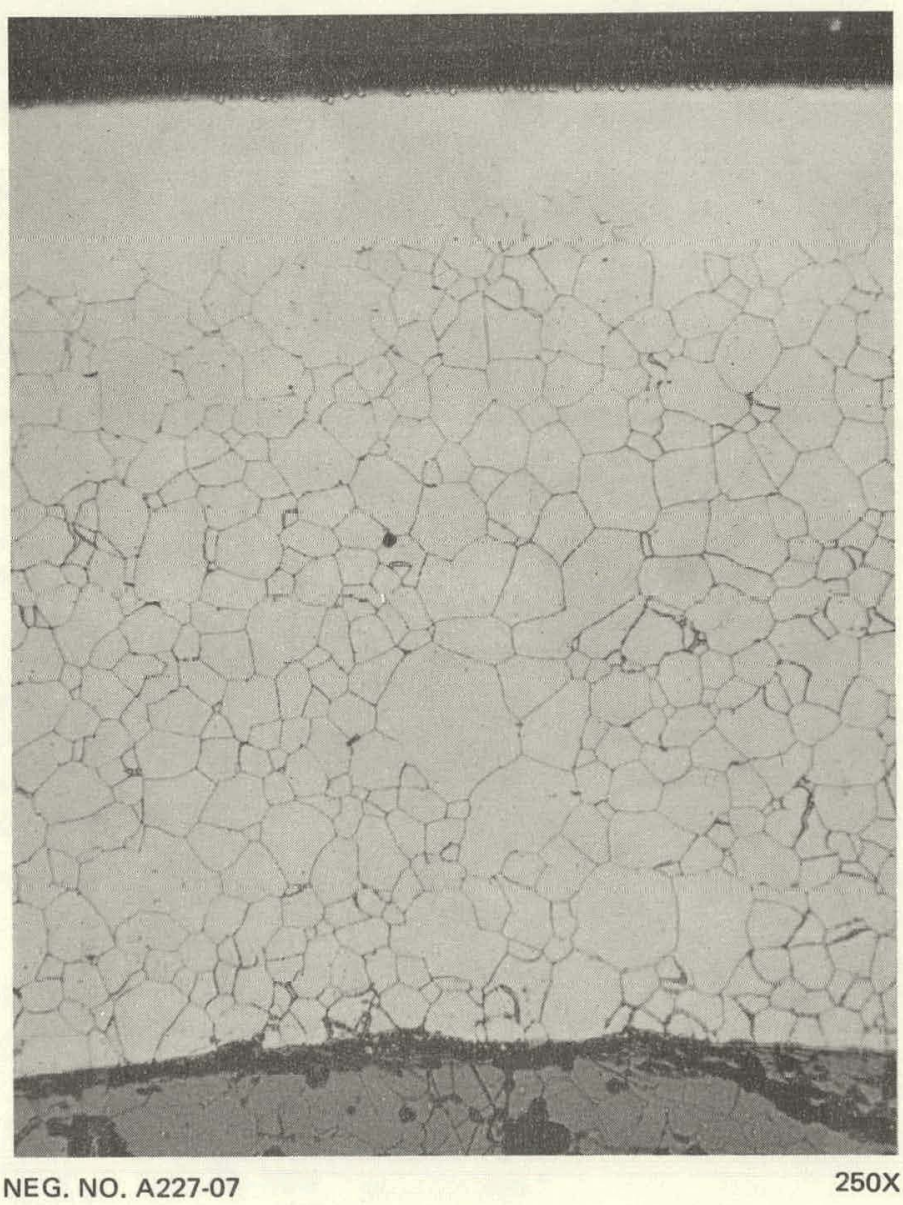

Figure 4-14. Cladding in the Etched Condition 


\subsection{POST-IRRADIATION THERMOCOUPLE CALIBRATION}

As described in Section 3.2, six "non-functional" W5Re/W26Re thermocouples were positioned outside of the test capsule to accumulate fluence in order to study transmutation-decalibration effects. These thermocouples were removed at the termination of the experiment and placed in storage in the GETR pool. The total neutron flux on the wires was assumed to be similar to that calculated for the capsule wall, and was as follows:

$\begin{array}{ll}\text { Thermal } & 1.9 \times 10^{20} \text { neutrons } / \mathrm{cm}^{2} \\ \text { Epithermal } & 2.1 \times 10^{20} \text { neutrons } / \mathrm{cm}^{2} \\ \text { Fast } & 0.53 \times 10^{20} \text { neutrons } / \mathrm{cm}^{2}\end{array}$

The irradiated thermoelements $(20 \mathrm{mil}$ diameter W5Re/W26Re) and alumina insulation were removed from their aluminum casings and the wires were found to be very brittle. A black, flakey deposit was observed on the insulators and wire, and indications were that water from the GETR pool had entered the tubing during irradiation (the thermoelements were exposed to temperatures of $\sim 100^{\circ} \mathrm{C}$ ). The hot junctions of these thermocouples, which had been formed by mechanical twisting and spot welding prior to the irradiation, were broken during removal from the aluminum tubing. New hot junctions were successfully formed on two of the thermocouples by crimping a piece of 1/16-inch diameter molybdenum-rhenium tubing around the wires. The segment was less than $1 / 8$-inch long with an approximate $42 \mathrm{mil}$ i.d. An unirradiated W5Re/W26Re thermocouple with the molybdenum-rhenium junction was tested to standardize the system.

Results from the two irradiated thermocouples are shown in Figure 4-15. Physical limitations of the test apparatus did not allow temperature measurements above $1200^{\circ} \mathrm{C}$. The data indicated a definite negative decalibration, which appeared to decrease with increasing temperature. An apparent anomaly observed at temperatures above $1000^{\circ} \mathrm{C}$ indicated that the thermoelectric output of the irradiated thermocouples decreased with time. No obvious explanation for this occurrence is available. Although scatter in the data is obvious, the trend indicated is similar to that previously observed by Novak and Asamoto. ${ }^{9}$ 


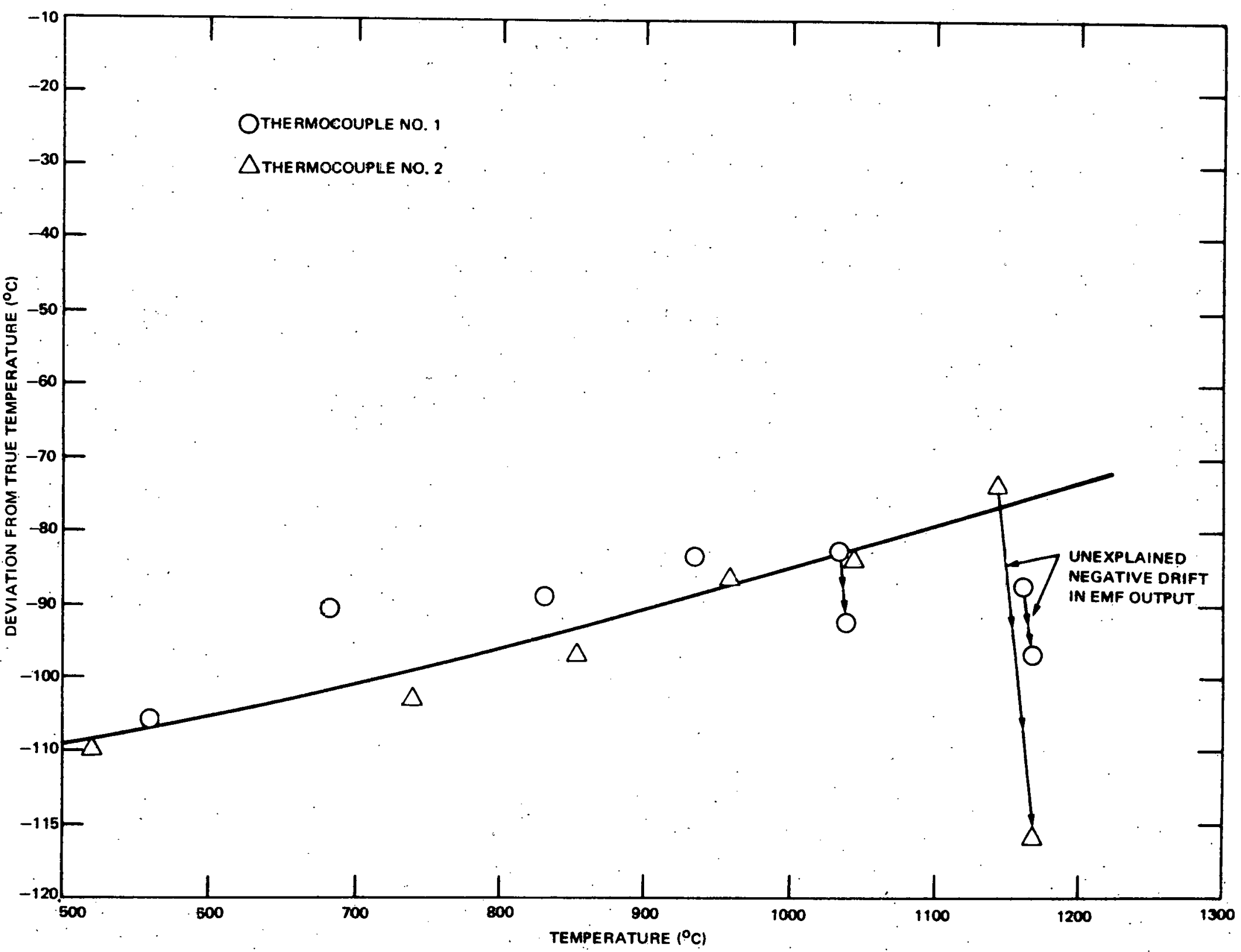




\section{DISCUSSION OF RESULTS}

Many variables are involved and must be carefully considered in attempting to evaluate the effective thermal conductivity of a plutonium-uranium oxide fuel directly in-reactor. The linear power, for example, is one of the more important parameters and is difficult to measure accurately. Evaluation of the data from this experiment indicated the many sources of potential errors in properly evaluating and utilizing thermocouple data. The circumferential temperature gradient observed could lead to significant errors in power calculations if the thermocouples were not oriented in the same angular plane lassuming differential temperature readings from thermocouples are used to calculate linear powers). Even with the proper orientation, uncertainties of 1 to $2 \mathrm{~kW} / \mathrm{ft}$ may be involved unless gamma heating effects are properly utilized.

The use of thermocouples to estimate cladding surface temperature presents another source of possible error. It was shown in this investigation that either of the two methods discussed in Appendix $E$ may be used to evaluate this temperature. The results of these two methods agreed quite well and demonstrated that significant error results when it is assumed that a thermocouple directly against the cladding surface is reading the cladding surface o.d. temperature. For example, the data indicate that a 1/16-inch $0 . d$. thermocouple will understate a cladding temperature of $1100^{\circ} \mathrm{F}$ by about $125^{\circ} \mathrm{F}$.

With the above factors (clad surface temperature and gamma heating) accounted for, the cladding inside surface temperature may be reasonably calculated. The heat transfer characteristics from this point to the geometric center of the fuel is related to three major parameters: (1) center temperature of the fuel; (2) the fuel-cladding gap coefficient; and (3) the thermal conductivity of the fuel.

Tungsten-rhenium thermocouples were selected to measure fuel center temperatures because of the relatively high temperatures to be monitored. Previous investigations $^{8} 9$ indicated that thermal embrittlement of the thermoelements and thermoelectric decalibration under an irradiation environment were the main areas of concern. The post-irradiation calibration of the non-functional tungsten-rhenium thermocouples strapped to the side of the capsule indicated that significant thermoelectric changes do occur. Refer to Section 4-6. The trend is similar to that previously reported, ${ }^{9}$ i.e., a negative decalibration at lower temperatures and approaching zero decalibration as temperature increases. This trend has also been found by other investigators. $^{10}$ On the other hand, studies with synthesized alloys of tungsten, rhenium, and osmium (simulating transmutation) have shown positive decalibration effects dependent on temperature, time, and exposure. ${ }^{11} 12$ In order to fully analyze this occurrence, one must consider the thermal spectrum, temperature gradients and compositional gradients (related to flux profile). The available data do suggest, however, that decalibration effects may induce errors on the order of 5 to $10 \%$.

With respect to the results of this investigation, the implications of the decalibration effect on the tungstenrhenium thermocouple data must be considered. In Figure 4-2, linear power values were plotted against center temperature. If the observed temperature increases were the result of thermocouple transmutation effects, the thermocouple, after 288 hours of irradiation, would have experienced a large positive decalibration. (This assumes that the initial data obtained during the first $\mathbf{4 8}$ hours in GETR are correct and not substantially influenced by thermocouple decalibration effects.) The post-irradiation check of the tungsten-rhenium thermocouples, however, showed a definite negative decalibration up to $1200^{\circ} \mathrm{C}$ Consequently, the actual increases in the fuel center temperatures may have been greater than those given in Figure 4-2.

No evidence of any significant irradiation induced decalibration of chromel/alumel thermocouples has been observed. ${ }^{13 / 15}$ it was therefore, felt that the cladding surface temperature as a function of linear power might provide some insight into the trends observed. Figure 5-1 illustrates the data taken on the various days. The information shows that while the fuel center temperature is gradually increasing, the apparent temperature increase is not being sensed by the cladding. This information, along with the thermocouple decalibration argument, suggests that a real decrease in the fuel conductivity and/or fuel-clad gap coefficient is occurring.

Values for fuel-cladding gap coefficients are not readily available. Craig, et al., ${ }^{6}$ have recently investigated this parameter for mixed oxides, with special attention on initial fuel-cladding gap. Their data for pins irradiated in a fast flux (helium cover gas) to $50,000 \mathrm{MWd} / \mathrm{Te}$ and at center temperature of about $2500^{\circ} \mathrm{C}$, indicate a gap coefficient of $1900 \mathrm{Btu} / \mathrm{hr} \mathrm{ft}^{2}{ }^{\circ} \mathrm{F}$ for pins with an initial $1 \mathrm{mil}$ gap. Projection of the linear relationship in Figure 4.5 to a fuel center temperature of $2500^{\circ} \mathrm{C}$, suggests a gap coefficient of $1875 \mathrm{Btu} / \mathrm{hr} \mathrm{ft}^{2}{ }^{\circ} \mathrm{F}$.

It is difficult to assess the contribution of gap coefficient to the increase in the fuel center temperature. It is believed that the linear relationship determined as a 


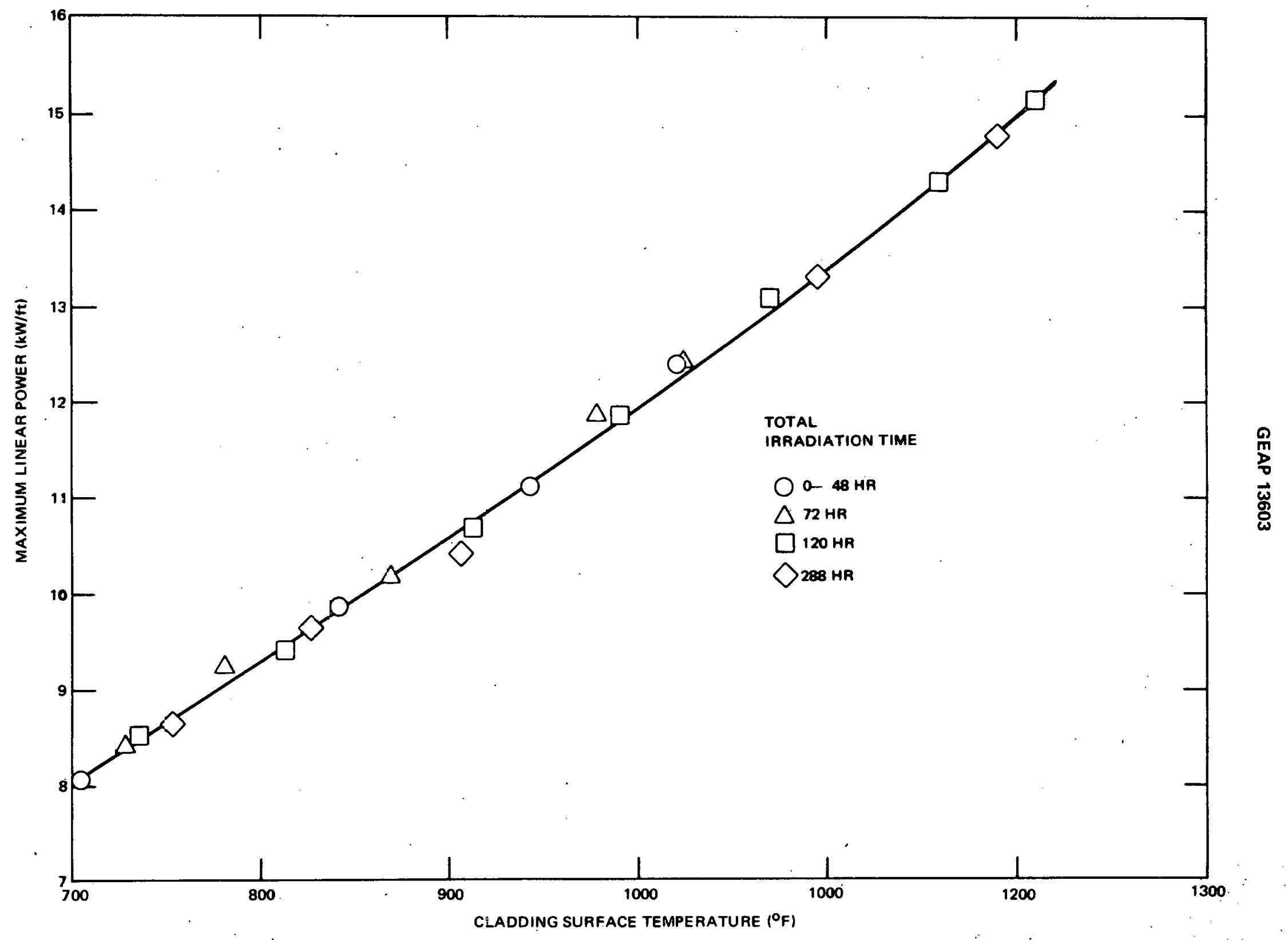

Figure 5-1. Relationship Between Fuet Cladding Surface Temperature and Linear Power 
function of temperature, Figure 4-9, is reasonable. A relatively large decrease in gap conductivity with time is difficult to justify on the basis of earlier experiments. ${ }^{4,6}$ The metallographic examination. Figure 4-11, indicated that an increasingly tight fuel-clad gap was maintained. There was no evidence of any significant reaction layer or intermediate interface that could cause a decrease in the gap coefficient.

On the basis of this experiment, the data has suggested that the fuel thermal conductivity, for fuel center temperatures between $1000^{\circ}$ and $2000^{\circ} \mathrm{C}$, does decrease during fuel operation. The apparent decrease in fuel conductivity at center temperatures less than $1600^{\circ} \mathrm{C}$ is primarily the result of thermal cracks and radiation damage of the fuel. The fact that the higher temperature data returns to the base integral curve, Figure 4-2, suggests the damage may have annealed out. Fuel surface temperatures of approximately $700^{\circ}$ and $900^{\circ} \mathrm{C}$ were calculated for corresponding center temperatures of $1100^{\circ}$ and $1600^{\circ} \mathrm{C}$ respectively. Experimental data ${ }^{16}$ indicate that pronounced decreases in the thermal conductivity of $\mathrm{UO}_{2}$ occurs after low temperature irradiation. The effect appears to remain to some degree even after specimens are annealed at temperatures above $1000^{\circ} \mathrm{C}$. The extent of recovery is dependent on neutron dose and the annealing temperature.

The apparent decrease in fuel conductivity measured after 288 hours of operation, cannot be explained by ir. radiation-damage. As previously described, in Section 3.3, the fuel pin operated at a constant power of $15 \mathrm{~kW} / \mathrm{ft}$ for about 150 hours. A fuel center temperature of $2000^{\circ} \mathrm{C}$ to $2100^{\circ} \mathrm{C}$ was maintained. Temperature profiles across the fuel ${ }^{*}$ during this time period are shown in Figure 5-2, and illustrate the relatively high surface temperature of the fuel.

A burnup effect with respect to the radial plutonium depletion was considered and for the burnups involved, no major contribution from this effect is apparent.

Based on the integral curve shown in Figure 4-4.
The data reviewed in reference 5 indicated that inreactor measurements of the thermal conductivity of $\mathrm{UO}_{2}$ between $500^{\circ}$ and $1800^{\circ} \mathrm{C}$, showed no difference from unirradiated values. While the properties of mixed plutoniumuranium oxides are similiar to those of $\mathrm{UO}_{2}$, one major difference does exist, which may contribute to the results observed in this investigation. When hypostoichiometric mixed oxides are placed under a large thermal gradient, oxygen migrates to the cooler portion of the fuel. Aitken ${ }^{17}$ has demonstrated this effect in mixed plutonium-uranium oxides having initial oxygen-to-metal ratios between 1.935 and 1.998. At temperatures less than $\sim 1200^{\circ} \mathrm{C}$, the thermal conductivity of mixed oxides is decreased by variations from the stoichiometric condition, ${ }^{18,19}$. consequently stoichiometry gradients may have contributed to the observed results. Unfortunately, predicted stoichiometry changes in this experiment would tend to reduce rather than cause it to increase.

A final factor, which must be considered with respect to the fuel thermal conductivity is microstructural changes. The thermal conductivity of uranium dioxide has been shown to increase markedly with density. ${ }^{20} \mathrm{~A}$ model was developed which incorporated density adjustment and corresponding thermal conductivity values for in-pile use. Integral curves adjusted for fuel densification were then generated. The net increase in the integral conductivity of initially $90 \%$ and $95 \%$ T.D. specimens was calculated to be $12 \%$ and $5.5 \%$ respectively. Based on the microstructures exhibited in Figure 4-19, an enhancement of approximately $3 \%$ in the fuel integral conductivity would be expected from the above model.

No conclusive explanation for the observed center temperature increase at constant power can be made. This same anomaly has been observed by two other investigators testing uranium dioxide in a similar manner. ${ }^{21,22}$ The experimental design, test conditions, and magnitude of the increase were very similar in all cases. The anomaly may be explained by one or a combination of the factors already discussed: 


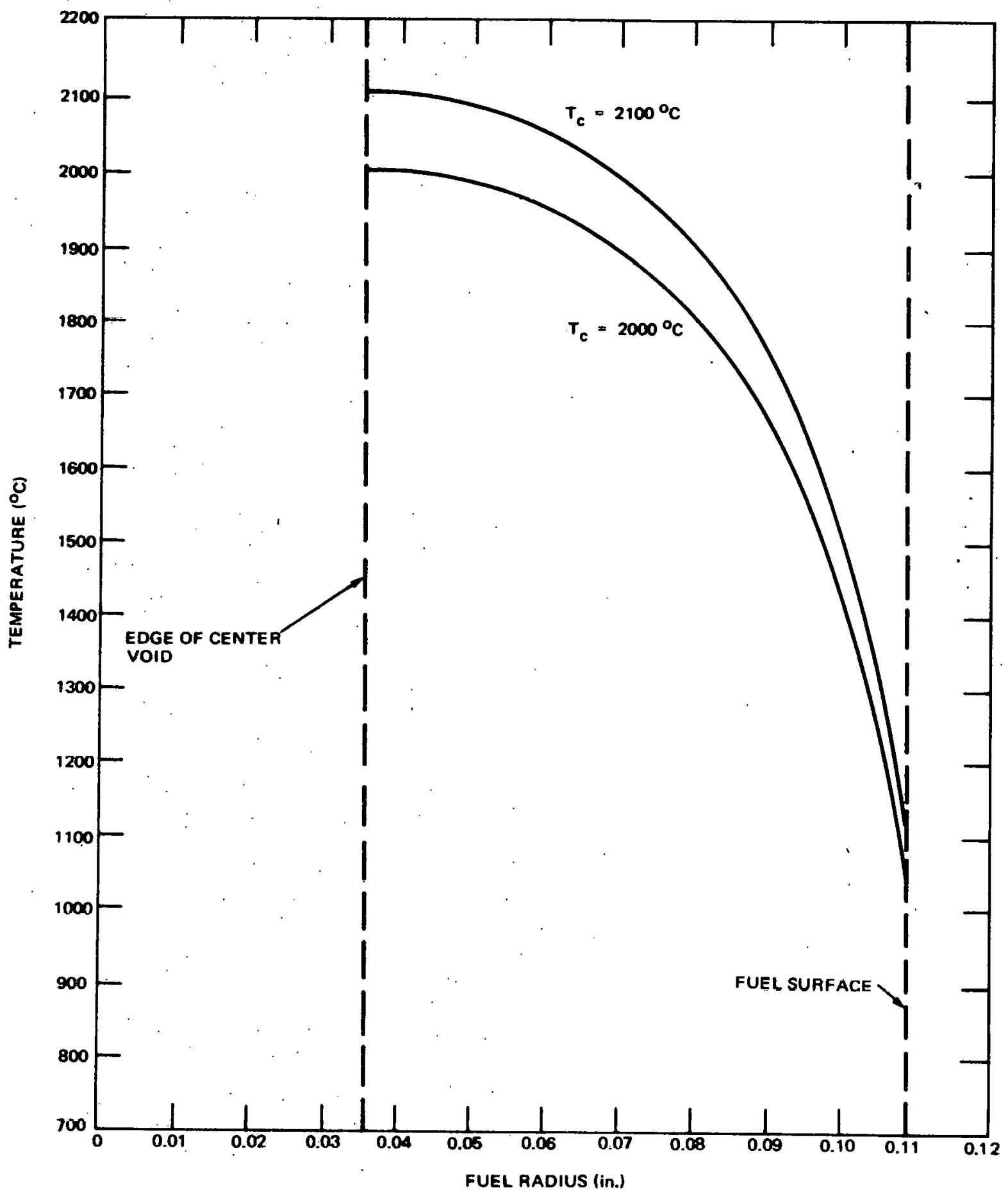

Figure 5-2. Temperature Profiles Across Fuel Operating at $15 \mathrm{~kW} / \mathrm{ft}$ 


\section{REFERENCES}

1. Christensen, J. A. and Allio, R. J., "In Pile Measurement of Uranium Dioxide Fuel Temperature Distribution," A.N.S. Transactions, 8, 1, p. 35, (1965).

2. Coplin, D. H., et al., The Thermal Conductivity of $\mathrm{UO}_{2}$ by Direct In-Reactor Measurement, March 1968. (GEAP-5100-6).

3. Sodium Cooled Reactors, Fast Ceramic Reactor Development Program, 12th Quarterly Report, JulySeptember 1964, November 1964, (GEAP-4723), pp. 5.1-5.4.

4. Sodium Cooled Reactors, Fast Ceramic Reactor Development Program, 13th Quarterly Report, October 1.964-January 1965. February 1965 (GEAP-4795), pp. 5.1-5.7.

5. Baily, W. E., et al., "Thermal Conductivity of Uranium-Plutonium Oxide Fuels," Nuclear Metallurgy, 13. International Symposium on Plu tonium Fuels Technology. Precedings of the 1967 Nuclear. Metallurgy Symposium held in Scottsdale, Arizona, on October 4-6, 1967, American Institute of Mining, Metallurgical, and Petroleum Engineers, Inc. (1968).

6. Craig, C. N., Hull, G. R., and Baily, W.E., Heat Transfer Coefficients Between Fuel and Cladding in Oxide Fuel Rods, January 1969, (GEAP-5748).

7. Sodium Cooled Reactors, Fast Ceramic Reactor Development Program, 20th Quarterly Report, August-October 1966, November 1966. (GEAP-5292).

8. Novak, P. E. and Asamoto, R. R., An Out-of-Pile Evaluation of $W$-Re Thermocouple Systems for Use to $4700^{\circ} \mathrm{F}$ in $\mathrm{PuO}_{2}-\mathrm{UO}_{2}$," GEAP-5166, June 1966.

9. Novak, P. E. and Asamoto, R. R., An In-Pile Evaluation of $W$-Re Thermocouple Systems for Use to $4700^{\circ} \mathrm{F}$ in SEFOR Fuel, October 1968 , (GEAP-5468).

10. Aspley, E. R., ed., Fast Flux Test Facility Quarterly Technical Report, July-September 1968. December 1968, (BNWL-917).

11. Kuhlman, W. C., Evaluation of Thermal Neutron Induced Errors in the WW25Re Thermocouple, 1965 (GE-TM-65-4-41).
12. Kuhlman, W. C., Thermocouple Research at GE-NMPO, February 1965, (GE-TM-65-2-15).

13. Dan, G. J., Bourassa, R. R., and Keeton, S. C., "Nuclear Radiation Dose Rate Influence on Thermocouple Calibration," Nucl. Appl., 5, 322 (1968).

14. Tranger, D. B., Experience with Stainless Steel Sheathed Chromel-Alumel Thermocouples in Irradiation Experiments, November 12, 1965. (ORNL-TM-1320).

15. Kelly, M. J., Change in LMF Characteristics of Chromel/Alumel and Platinum/Platinum-Rhodium, TID-7586(Pt-1), High Temperature Thermometry Seminar held October 1.2, 1959, at Oak Ridge National Laboratory.

16. Thermal Conductivity of Uranium Dioxide, report of the panel on thermal conductivity of uranium dioxide held in Vienna, April 26-30, 1965; Technical Report Series No. 59, International Atomic Energy. Agency, Vienna, (1966).

17. Aitken, E. A., "Thermal Diffusion in Closed Oxide Fuel Systems," J. Nucl. Matl., 30, pp. 62-73, (1969).

18. Van Cracynest, J. D. and Weilbacher, J., "Study of the Thermal Conductivity of Mixed Uranium and Plutonium Oxides," J. Nucl. Matl., 26, pp. 132-136, (1968).

19. Gibby, R. L., The Effect of Oxygen Stoichiometry on the Thermal Diffusivity and Conductivity of $U_{0.75} P u_{0.25} / 2$ - x. January 1969, (BNWL-927).

20. Asamoto, R. R., Anselin, F. L., and Conti, A. E., "The Effect of Density on the Thermal Conductivity of Uranium Dioxide," J. Nucl. Matl., 29, pp.67-81, (1969).

21. Christensen, J. A., and Allio, R. J., "In-Pile Measurement of Uranium Dioxide Fuel-Temperature Distribution," ANS Trans., 8, 1,pp. 40-41, (1965).

22. Kjaerheim, G., and Rolstad, E., In-Pile Determination of $\mathrm{UO}_{2}$ Thermal Conductivity Density Effects and Gap Conductance, December 1967, (HPR-80).

23. Dwork, J., Self-Shielding Factors for Infinitely Long Hollow Cylinders, January 10, 1955, (KAPL-1262). 


\section{APPENDIX A}

\section{TUNGSTEN-RHENIUM THERMOCOUPLES}

Two tungsten-rhenium thermocouples were fabricated for use in this experiment. The thermocouples were sheathed in 1/16-inch o.d. vapor deposited tungsten-22 \pm 2 $w / \%$ rhenium tubing with a 10 mil wall, and insulated with double-bore, high-fired beryllia insulation. A typical chemical analyses of the ultra-high-purity beryllia is shown in Table A-1. The thermoelements were 5 mil diameter, tungsten $-5 \mathrm{w} / \%$ rhenium and tungsten-26 $w / \%$ rhenium. The manufacturer's* calibration data for the lot of wire used is listed in Table A-2.

* Hoskins Manufacturing Company

* Continental Sensing, Inc.

TABLE A-1

TYPICAL CHEMICAL ANALYSIS OF ULTRA-HIGH-PURITY (99.9 PERCENT) BeO

\section{BeO Content}

Impurities (ppm)

$\begin{array}{lr}\text { Aluminum } & 150 \\ \text { Bürüı } & \leq 5 \\ \text { Calcium } & 50 \\ \text { Chromium } & <10 \\ \text { Copper } & <10 \\ \text { Iron } & 20 \\ \text { Potassium } & 50 \\ \text { Lithium } & <10 \\ \text { Magnesium } & 50 \\ \text { Manganèsė } & <10 \\ \text { Sodium } & 30 \\ \text { Nickel } & <10 \\ \text { Silicon } & 200 \\ \text { Strontium } & <10 \\ \text { Titanium } & <10 \\ \text { Vanadium } & <10 \\ \text { Zinc } & <20 \\ \text { Zirconium } & <10\end{array}$

The thermocouples were of a grounded design and sealed under an argon atmosphere. A stainless steel transition piece joined the tungsten-rhenium sheath to a 316 SS sheathed compensated lead wire. The wires were brazed within the transition piece, which was located just outside the fuel pin (the transition piece was also the end plug for the fuel pin). The magnesia insulated compensated lead wire (405/426) was extended to a continuous two pen recorder. The vendor ${ }^{* *}$ verified similarities in the thermoelectric outputs of the compensated lead wire and the W5Re/W26Re thermocouples to $1100^{\circ} \mathrm{F}$. Their results showed deviations of 1,2 , and $3^{\circ} \mathrm{F}$ at $500^{\circ}, 800^{\circ}$, and $1100^{\circ} \mathrm{F}$ respectively.
TABLE A-2

CALIBRATION DATA FOR TUNGSTEN-RHENIUM THERMOCOUPLES

Temperature, ${ }^{\circ} \mathrm{F}\left({ }^{\circ} \mathrm{C}\right)$

EMF (mv)

$\begin{array}{ll}200 & (93) \\ 400 & (204) \\ 600 & (316) \\ 800 & (427) \\ 1000 & (538) \\ 1200 & (649) \\ 1400 & (760) \\ 1600 & (8 / 1) \\ 1800 & (982) \\ 2000 & (1093) \\ 2200 & (1204) \\ 2400 & (1316) \\ 2600 & (1427) \\ 2800 & (1538) \\ 3000 & (1649) \\ 3200 & (1760) \\ 3400 & (1871) \\ 3600 & (1982)\end{array}$

1.263

3.042

5.041

7.143

9.277

11.432

13.573

15.672

17.742

19.749

21.715

23.606

25.433

27.156

28.843

30.448

31.925

33.380 


\section{APPENDIX B}

\section{FUEL PELLET PARAMETERS}

The mixed oxide fuel pellets used in this experiment were made from two batches of powder. The $\mathrm{PuO}_{2}$ content, percent enrichment, plutonium isotopic distribution and stoichiometry for each batch of sintered pellets are listed in Table B-1. The specific parameters for each fuel pellet, and each insulator and blanket pellet are listed in
Table B-2. The pellets are listed in the order they were located in the fuel pin, i.e., pellet No. 1 was at the top of the fuel pin. The length of the fuel column was measured in a v-trough prior to loading, and is compared in Table B-3 to the sum of the individual pellet measurements from Table B-2.

TABLE B-1

ISOTOPIC DISTRIBUTION OF FUEL BATCHES

AND STOICHIOMETRY OF SINTERED PELLETS

UTILIZED IN CAPSULE EIAA

BATCH 314

BATCH 284

$$
\begin{gathered}
\text { Pu-239 } \\
w / \%
\end{gathered}
$$
Pu-240
$w / \%$
Pu-241
$w / \%$
Pu-242
$w / \%$
U-235
$w / \%$

$\mathrm{O} / \mathrm{M}$

$$
w / \%
$$

20.28

19.4
8.49

8.35
0.79

0.77
90.84

ANALYTICAL RESULTS (INSULATOR AND BLANKET)

BATCH U.63

$\% U-235-0.82 \quad O / M-1.998$

TABLE B-2

\begin{tabular}{|c|c|c|c|c|c|c|}
\hline $\begin{array}{c}\text { Pellet } \\
\text { No. }\end{array}$ & $\begin{array}{c}\text { Batch } \\
\text { No. }\end{array}$ & $\begin{array}{r}\text { Diameter } \\
\text { (Inches) }\end{array}$ & $\begin{array}{l}\text { Length } \\
\text { (Inches) }\end{array}$ & $\begin{array}{c}\text { Weight } \\
\text { (gm) }\end{array}$ & $\begin{array}{c}\text { Annulus } \\
\text { (Mils) }\end{array}$ & $\begin{array}{l}\text { s Density } \\
\text { (\% T.D.) }\end{array}$ \\
\hline 1 & \multicolumn{6}{|c|}{ Stainless Steel Dummy Pellet 0.2197 in. o.d. $\times 0.253$ in. Long* } \\
\hline 2 & U-63 & 0.2127 & 0.2567 & 1.317 & 78 & 93.0 \\
\hline 3 & & 0.2129 & 0.2551 & 1.356 & 75 & 95.0 \\
\hline 4 & U.63 & 0.2128 & 0.2560 & 1.358 & 76 & 95.3 \\
\hline 5 & B-284 & 0.2189 & 0.2503 & 1.394 & 74 & 92.3 \\
\hline 6 & & 0.2190 & 0.2403 & 1.343 & 74 & 92.5 \\
\hline 7 & & 0.2190 & 0.2477 & 1.373 & 74 & 91.8 \\
\hline 8 & & 0.2189 & 0.2573 & 1.431 & 74 & 92.1 \\
\hline 9 & & 0.2189 & 0.2553 & 1.417 & 74 & 92.0 \\
\hline 10 & & 0.2189 & 0.2404 & 1.330 & 74 & 91.7 \\
\hline 11 & & 0.2189 & 0.2541 & 1.410 & 73 & 91.6 \\
\hline 12 & & 0.2189 & 0.2510 & 1.397 & 73 & 91.9 \\
\hline 13 & & 0.2189 & 0.2667 & 1.477 & 73 & 91.5 \\
\hline
\end{tabular}

SPECIFIC PARAMETERS OF

PELLETS IN FUEL PIN EIAA 
Table B-2 (Continued)

\begin{tabular}{|c|c|c|c|c|c|c|c|}
\hline $\begin{array}{l}\text { Pellet } \\
\text { No. }\end{array}$ & $\begin{array}{l}\text { Batch } \\
\text { No. }\end{array}$ & $\begin{array}{l}\text { Diameter } \\
\text { (Inches) }\end{array}$ & $\begin{array}{l}\text { Length } \\
\text { (Inches) }\end{array}$ & $\begin{array}{c}\text { Weight } \\
\text { (gm) }\end{array}$ & $\begin{array}{c}\text { Annulus } \\
\text { (Mils) }\end{array}$ & $\begin{array}{l}\text { Density } \\
\text { (\% T.D.) }\end{array}$ & \\
\hline 14 & & 0.2190 & 0.2463 & 1.369 & 73 & 91.7 & \\
\hline 15 & & 0.2189 & 0.2906 & 1.603 & 74 & 91.4 & . \\
\hline 16 & & 0.2190 & 0.2586 & 1.451 & 74 & 92.9 & \\
\hline 17 & & 0.2189 & 0.2242 & 1.255 & 74 & 92.8 & \\
\hline 18 & & 0.2189 & 0.2460 & 1.380 & 74 & 92.9 & \\
\hline 19 & & 0.2189 & 0.2542 & 1.423 & 74 & 92.8 & \\
\hline 20 & & 0.2189 & 0.2512 & 1.392 & 73 & 91.5 & \\
\hline 21 & B-284 & 0.2189 & 0.2446 & 1.360 & 73 & 91.8 & \\
\hline 22 & B-314 & 0.2189 & 0.2543 & 1.436 & 72 & 92.9 & 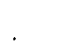 \\
\hline 23 & & 0.2189 & 0.2519 & 1.423 & 72 & 92.9 & \\
\hline 24 & & 0.2190 & 0.2107 & 1.196 & 72 & 93.3 & \\
\hline 25 & & 0.2191 & 0.2550 & 1.430 & 72 & 92.1 & \\
\hline 26 & . & 0.2192 & 0.2484 & 1.400 & 72 & 92.5 & \\
\hline 27 & & 0.2189 & 0.2474 & 1.402 & 72 & 93.2 & \\
\hline 28 & B-314 & 0.2189 & 0.2482 & 1.392 & 72 & 92.2 & \\
\hline 29 & U-63 & 0.2130 & 0.2561 & 1.376 & 73 & 95.2 & \\
\hline 30. & & 0.2130 & 0.2561 & 1.373 & 74 & 95.3 & \\
\hline 31 & U.63 & 0.2128 & 0.2566 & 1.374 & 73 & 95.1 & \\
\hline 32 & Stainless & eel Dumm & ny Pellet & 0.2197 & o.d. $\times 0$ & 0.253 in & $\mathrm{hg}$. \\
\hline
\end{tabular}

\footnotetext{
- Stainless steel dummy pellets acted as guides to center Tungsten-Rhenium thermocouples.
}

TABLE B-3

FUEL COLUMN LENGTH

\begin{tabular}{|c|c|c|}
\hline & $\begin{array}{l}\text { Medsured } \\
\text { Length } \\
\text { (Inches) }\end{array}$ & $\begin{array}{l}\text { Tabulāted } \\
\text { Length" } \\
\text { (Inches) }\end{array}$ \\
\hline Blanket & 1.025 & 1.0219 \\
\hline Fuel & 5.978 & 5.9947 \\
\hline Insulator & 1.022 & 1.0209 \\
\hline otal Length & 8.025 & 8.0375 \\
\hline
\end{tabular}

* Sum of individual pellet lengths from Table B-2. Values for the blanket and insulator pellets include the stainless steel dummy pellets. 


\section{APPENDIX C}

\section{THERMAL CONDUCTIVITY CURVES FOR} 304 SS, 316 SS, 321 SS, Zircaloy-2 AND NaK

Evaluation of data obtained from capsule EIAA required a knowledge of the thermal conductivity of 304 SS, 316 SS, 321 SS, Zircaloy-2, and NaK. A literature review was made to obtain values for these materials, and polynomial expressions were derived which best fit the available data. The polynomials used were as follows:

\begin{tabular}{lcc} 
& $\begin{array}{c}\text { Applicable } \\
\text { Temperature } \\
\text { Range ( }{ }^{\circ} \mathrm{F} \text { ) }\end{array}$ & \multicolumn{1}{c}{$\begin{array}{c}\text { Thermal Conductivity Expression } \\
\text { (Btu/hr-ft- }{ }^{\circ} \mathrm{F} \text { ) }\end{array}$} \\
$304 \mathrm{SS}$ & $150 \leqslant \mathrm{~T} \leqslant 1300$ & $\mathrm{~K}=7.4398+7.3575 \times 10^{-3} \mathrm{~T}-2.0937 \times 10^{-6} \mathrm{~T}^{2}$ \\
$316 \mathrm{SS}$ & $0 \leqslant \mathrm{~T} \leqslant 1800$ & $\mathrm{~K}=7.4470+5.6800 \times 10^{-3} \mathrm{~T}-1.6576 \times 10^{-6} \mathrm{~T}+8.0306 \times 10^{-10} \mathrm{~T}^{3}$ \\
$321 \mathrm{SS}$ & $100 \leqslant \mathrm{~T} \leqslant 1200$ & $\mathrm{~K}=8.2673+4.7601 \times 10^{-3} \mathrm{~T}$ \\
Zircaloy-2 & $110 \leqslant \mathrm{~T} \leqslant 1500$ & $\mathrm{~K}=7.1647+2.5003 \times 10^{-3} \mathrm{~T}+1.1846 \times 10^{-6} \mathrm{~T}^{2}$ \\
NaK & $100 \leqslant \mathrm{~T} \leqslant 1350^{\circ} \mathrm{F}$ & $\mathrm{K}=12.2899+1.2634 \times 10^{-5} \mathrm{~T}+2.4085 \times 10^{-5} \mathrm{~T}^{2}-4.9388 \times 10^{-8} \mathrm{~T}^{3}$
\end{tabular}.

\section{APPENDIX D}

\section{GAMMA HEATING}

Neglecting gamma heating effects produces systematic errors in the calculated linear powers. The extent of these errors is directly related to the mass of material in the capsule and the neutron flux. For this experiment, thermocouple pairs in the same radial plane produced linear powers which varied as much as $1.5 \mathrm{~kW} / \mathrm{ft}$ when gamma heating was ignored. This was the result of a radial generation of heat which caused the outer thermocouples to record higher than normal temperatures. In order to make the correction for gamma heating, it was assumed that (1) the inner thermocouples next to the fuel cladding were affected negligibly by the gamma heating; and (2) linear power calculated by using the mid and inner thermocouples in a group would be somewhat biased by gamma heating. An independent calculation was made based on.mass and neutron flux. Based on this calculation, $0.25 \mathrm{~kW} / \mathrm{ft}$ were added to the linear power calculated from the inner and mid thermocouples. This was assumed to be the actual power unbiased by gamma heating. Using this value for linear power, a back calculation was made to. determine the unbiased temperatures of the mid and outer thermocouples. These calculated temperatures were well below what the thermocouples were reading. This calculation was repeated at various times for each pair of thermocouples in the four thermocouple "sets." (Refer to Section 3.2 for the definition of a thermocouple "set.") The difference between the observed and calculated temperature of the outer-most thermocouples was found to be as great as $100^{\circ} \mathrm{F}$.

With the above correction incorporated into the linear power calculation, values from various "sets" of thermocouples at a given time generally agreed within $\pm 0.1 \mathrm{~kW} / \mathrm{ft}$. 


\section{APPENDIXE}

\section{DETERMINATION OF FUEL CLAD SURFACE TEMPERATURE}

The fuel clad surface temperature was determined by two methods. The first method involved using the thermal conductivity of NaK. It was assumed that the temperature recorded by a thermocouple next to the cladding was the same as the temperature of NaK located at the geometric center of that thermocouple. The second method involves linear extrapolation of thermocouple temperatures to the clad surface.

It had previously been observed that the temperature measured by thermocouples around the fuel cladding were directly proportional to the radius of the thermocouple. ${ }^{9}$ Assuming uniform radial heat dissapation from the fuel pin. the data from $20 \mathrm{mil}$ and 1/16-inch diameter thermocouples at different angular locations next to the fuel cladding showed as much as 50 to $60^{\circ} \mathrm{F}$ difference in readings taken at the same time. Before data from the $20 \mathrm{mil}$ and 1/16-inch thermocouples could be compared for a linear extrapolation of cladding temperature, this angular temperature variation had to be accounted for.

A linear relationship was found to exist between a fuel cladding thermocouple and the other thermocouples in that set. That is, for any temperature measured by a cladding thermocouple, there was always a related temperature for the middle thermocouple and the outer thermocouple in that set. In both sets of thermocouples employing a 1/16-inch thermocouple next to the cladding, the same relation was found to exist. ${ }^{*}$ The linear relationship for the case of a 1/16-inch thermocouple next to the cladding is shown in Figure E-1 and for a $20 \mathrm{mil}$ thermocouple in Figure E-2. It becomes evident that with the above graphs the remperatures of both a $20 \mathrm{mil}$ and $1 / 16$-inch cladding thermocouple may be determined at any angular position in the capsule where there were thermocouples. This is true regardless of whether or not a $20 \mathrm{mil}$ or $1 / 16$ inch thermocouple actually existed at that angular position.

* The capsule was regularly adjusted in the V-raft facility to assure that the thermocouples in the two horizontal planes were at the same power.
Using the above technique, a plot of temperature versus thermocouple radius could be made, Figure E-3. Extrapolation of the thermocouple data to a radius of zero indicated the outside surface temperature of the fuel clad. ding. Agreement was excellent between cladding surface temperatures determined graphically and temperatures rigorously calculated using the thermal conductivity of $\mathrm{NaK}$ across the thermocouple radius. Table E- 1 shows temperatures determined by both methods for 10 observations in which the disagreement averages less than $\pm 3^{\circ} \mathrm{F}$ for a temperature range of 720 to $1220^{\circ} \mathrm{F}$. The significance of this evaluation is the error involved if the cladding surface temperature is assumed to be that of the thermocouples in intimate contact with the cladding, e.g. $\sim 125^{\circ} \mathrm{F}$ for 1/16-inch diameter thermocouple at $1100^{\circ} \mathrm{F}$. The error appears to increase with temperature. For the purpose of this report, the geometric technique was used to determine fuel cladding surface temperatures.

As previously noted, there was an apparent circumferential variation in temperature in the capsule. Thermocouple outputs showed that the four sets of thermocouples followed a consistent pattern, i.e., one set of thermocouples always read higher than another. The small initial cold gap assured that fuel-cladding esreentricity would not be a factor. The variation is presumed to be caused by the difference in angular orientation of the thermocouples with respect to the reactor core. Considering the near symmetry of cladding temperatures at positions adjacent to thermocouples 6 and 7, a hypothetical orientation of the capsule with respect to the core could be determined, Figure E-4. Also included in the figure is a table showing calculated cladding surface temperatures at various times. At the higher temperatures the variation in surface temperature recorded was as much as 50 to $60^{\circ} \mathrm{F}$. If this is extrapolated from the peak temperature, near thermocouple 18, to a point on the opposite side of the fuel cladding, a temperature gradient of as much as $100^{\circ} \mathrm{F}$ may be postulated to exist around the cladding. 


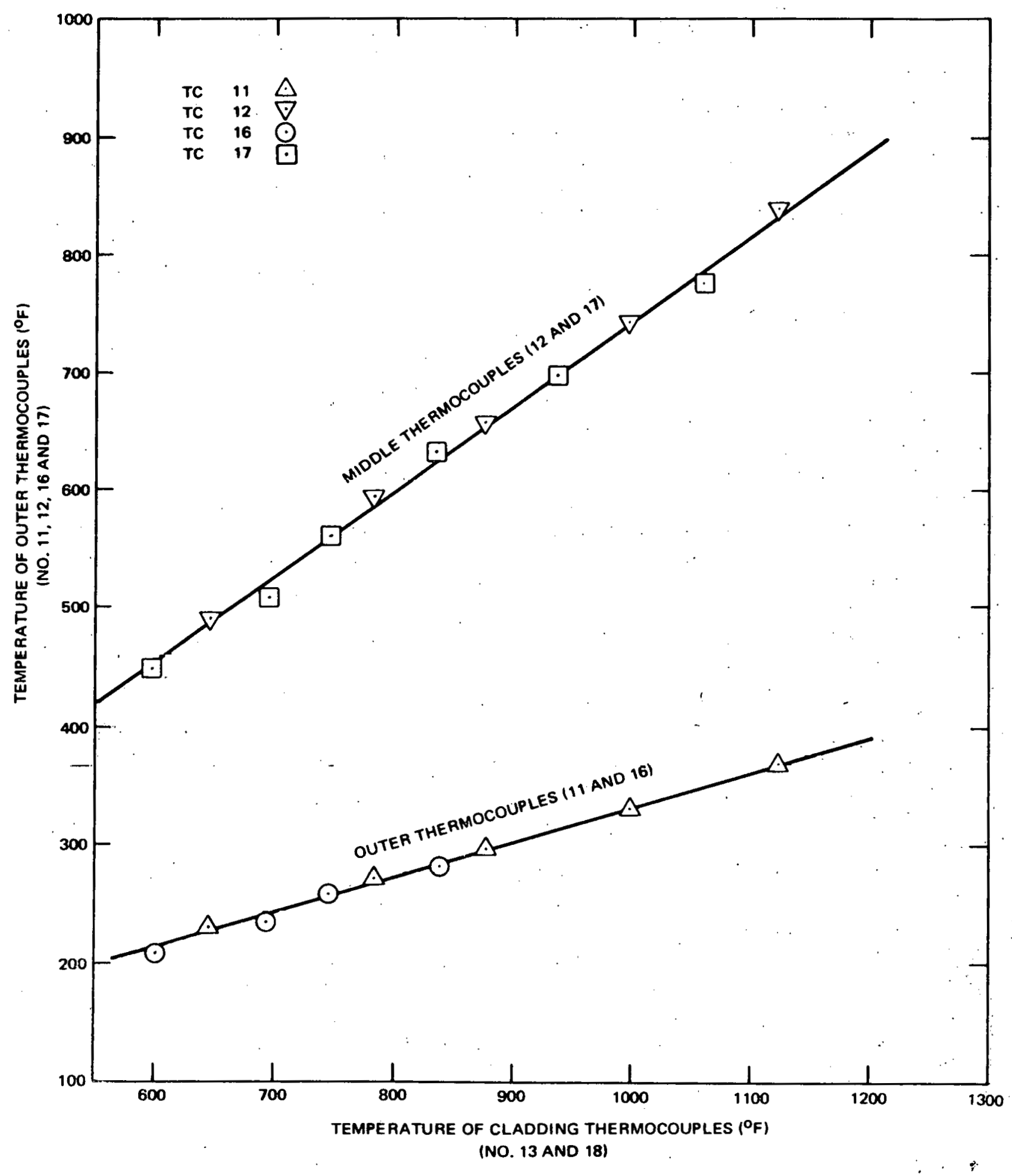

Figure E-1. Relation of Outer Thermocouples to $1 / 16$ Inch Thermocouples Next to Fuel Cladding 


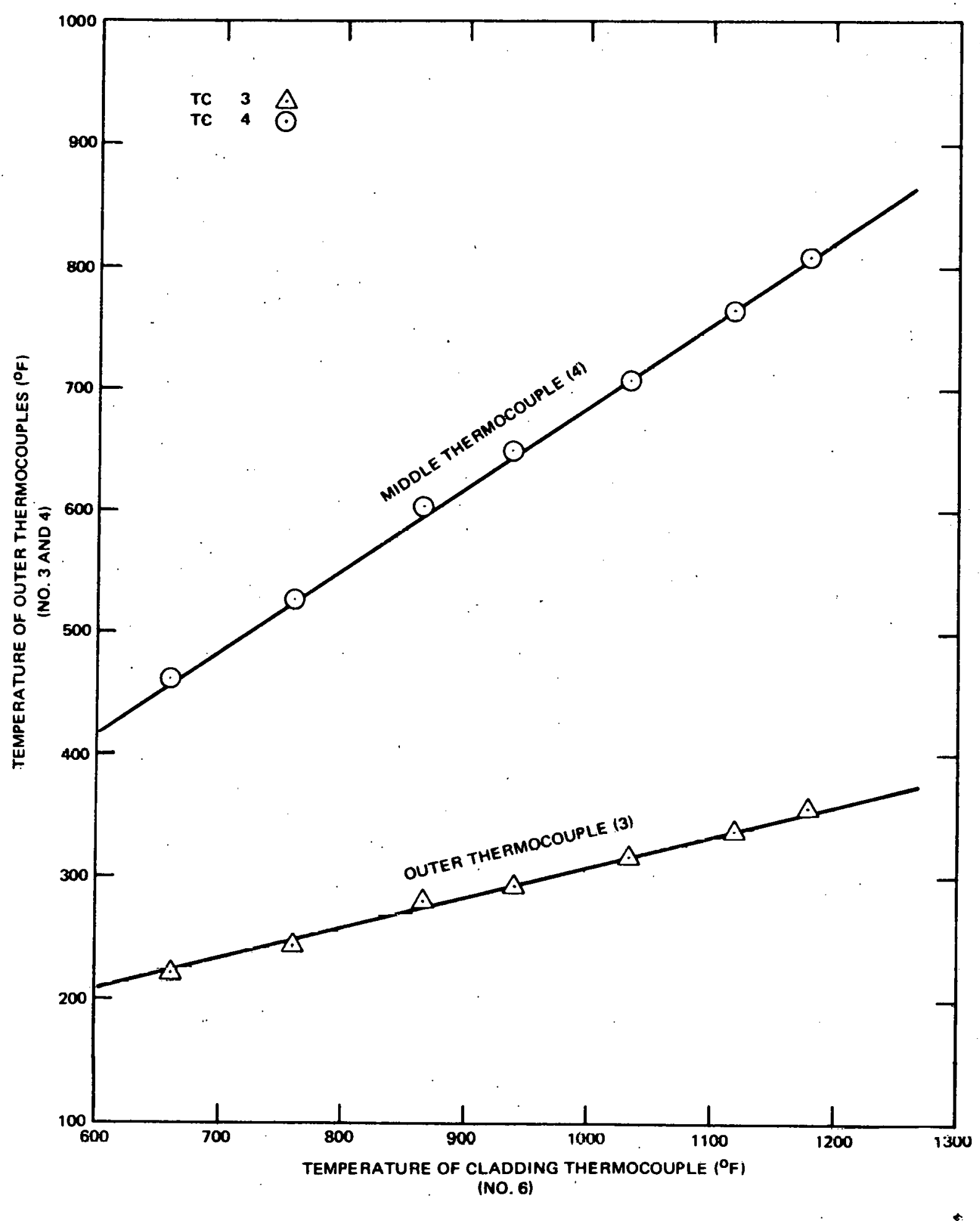

Figure E-2. Relation of Outer Thermocouples to a 20 Mil Thermocouple Next to the Fuel Cladding 


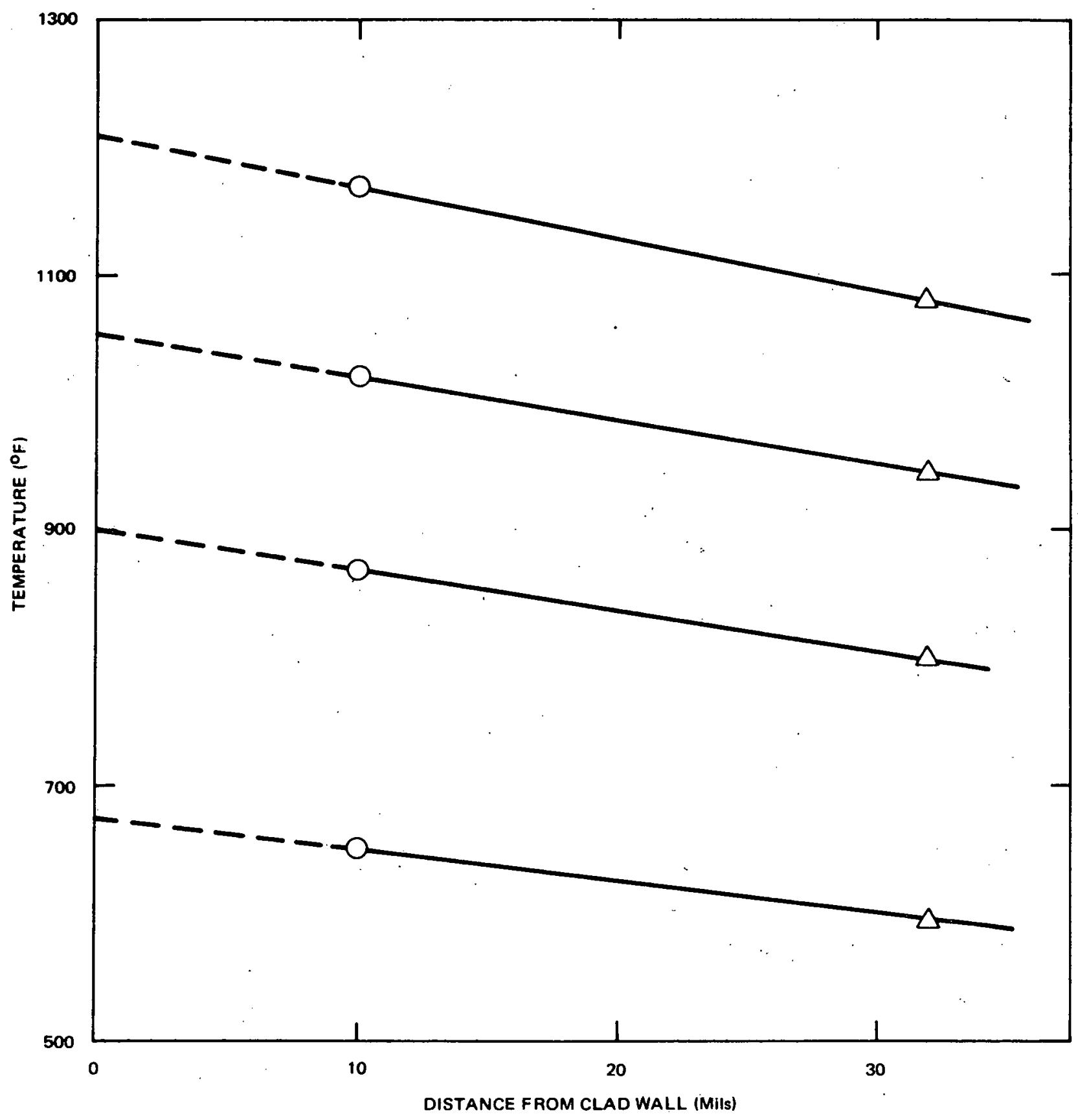

Figure E-3. Cladding Surface Temperature Determined Using a 20 Mil and 62 Mil Thermocouple 


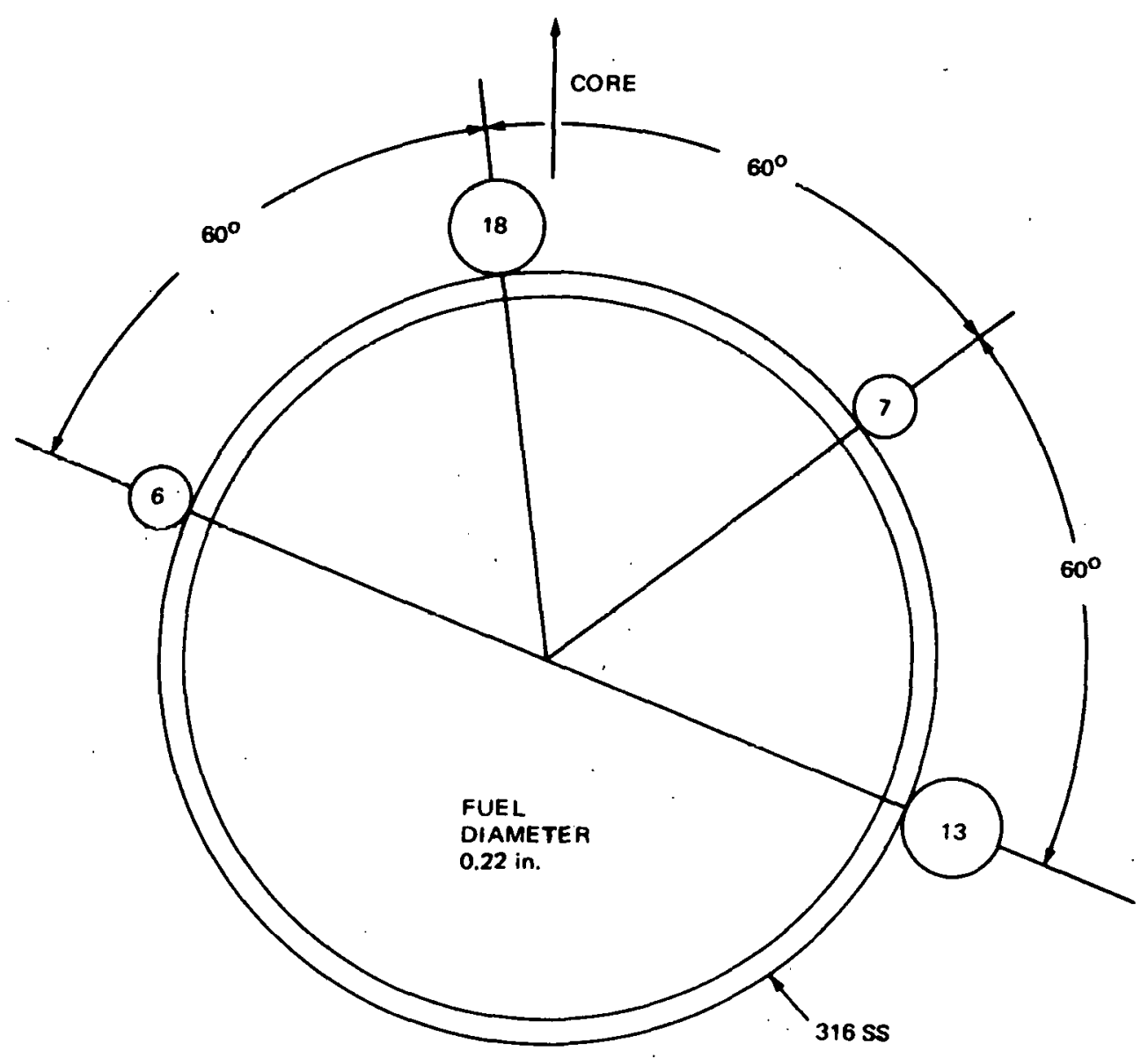

THERMOCOUPLE DIAMETERS: NO.'s 6 AND $70.020 \mathrm{in.}$ NO.'s 13 AND 180.062 in.

\begin{tabular}{|c|c|c|c|c|}
\hline CENTER TEMPERATURE & DATODt & T.C. NO. & T.C. TEMPERATURE & CLAD TEMPERATURE $+\dagger$ \\
\hline $\begin{array}{l}1188^{\circ} \mathrm{C} \\
1188^{\circ} \mathrm{C} \\
1188^{\circ} \mathrm{C} \\
1188^{\circ} \mathrm{C}\end{array}$ & $\begin{array}{ll}8-8, & 24: 00 \\
6-8, & 24: 00 \\
6--8, & 24: 00 \\
6-8, & 24: 00\end{array}$ & $\begin{array}{r}6 \\
18 \\
7 \\
13\end{array}$ & $\begin{array}{l}658^{\circ} \mathrm{F} \\
639 \\
665^{*} \\
595\end{array}$ & $\begin{array}{l}680^{\circ} \mathrm{F} \\
701 \\
686 \\
654\end{array}$ \\
\hline $\begin{array}{l}1860^{\circ} \mathrm{C} \\
1660^{\circ} \mathrm{C} \\
1660^{\circ} \mathrm{C} \\
1660^{\circ} \mathrm{C}\end{array}$ & $\begin{array}{ll}6-7, & 20: 00 \\
6-7, & 20: 00 \\
6-7, & 20: 00 \\
6-7, & 20: 00\end{array}$ & $\begin{array}{r}6 \\
18 \\
7 \\
13\end{array}$ & $\begin{array}{c}987 \\
945 \\
1010^{*} \\
900\end{array}$ & $\begin{array}{r}1021 \\
1043 \\
1045 \\
997 \\
\end{array}$ \\
\hline $\begin{array}{l}1873^{\circ} \mathrm{C} \\
1873^{\circ} \mathrm{C} \\
1873^{\circ} \mathrm{C} \\
1873^{\circ} \mathrm{C}\end{array}$ & $\begin{array}{l}6-10,15: 08 \\
6-10,15: 08 \\
6-10,15: 08 \\
6-10,15: 08\end{array}$ & $\begin{array}{r}6 \\
18 \\
7 \\
13\end{array}$ & $\begin{array}{l}1122 \\
1084 \\
1190 \\
1015\end{array}$ & $\begin{array}{l}1162 \\
1205 \\
1191 \\
1140\end{array}$ \\
\hline $\begin{array}{l}2110^{\circ} \mathrm{C} \\
2110^{\circ} \mathrm{C} \\
2110^{\circ} \mathrm{C} \\
2110^{\circ} \mathrm{C}\end{array}$ & $\begin{array}{l}6-14,4: 00 \\
6-14,4: 00 \\
6-14,4: 00 \\
6-14,4: 00\end{array}$ & $\begin{array}{r}6 \\
18 \\
7 \\
13 \\
\end{array}$ & $\begin{array}{l}1172 \\
1110 \\
1185 \\
1060\end{array}$ & $\begin{array}{l}1213 \\
1233 \\
1226 \\
1182 \\
\end{array}$ \\
\hline \multicolumn{2}{|c|}{$\begin{array}{l}\text {-DETERMINED FROM OUTER } \\
\text { THERMOCOUPLES }\end{array}$} & $\begin{array}{l}\text { tDATE } \\
\text { T+DETER }\end{array}$ & $\begin{array}{l}\text { TIME OF DAY } \\
\text { D B BY.LINEAR EXTF }\end{array}$ & LATIION \\
\hline
\end{tabular}

Figure E-4. Cladding Temperature Related to Thermocouple Temperature 
TABLE E-1

COMPARISON OF FUEL CLAD TEMPERATURES

PREDICTED BY CALCULATION AND A

GEOMETRIC APPROACH

$\begin{array}{cccc}\text { TC No. } & \begin{array}{c}\text { Clad Temperature } \\ \text { By Calculation ( }\end{array} \text { F) } & \begin{array}{c}\text { Clad Temperature by } \\ \text { Geometric Method ( }\end{array} & \text { F) } \\ \text { Difference ( } & \text { F) } \\ 6,18 & 724 & 723 & +1 \\ 6,18 & 784 & 788 & -4 \\ 6,18 & 894 & 887 & +7 \\ 6,18 & 941 & 938 & +3 \\ 6,18 & 969 & 970 & -1 \\ 6,18 & 1022 & 1025 & -3 \\ 6,18 & 1068 & 1069 & -1 \\ 6,18 & 1162 & 1163 & -1 \\ 6,18 & 1203 & 1209 & -6 \\ 6,18 & 1221 & 1220 & +1\end{array}$

\section{APPENDIX F}

\section{FLUX.DEPRESSION.FOR EIAA}

In a thermal reactor, mixed oxide fuel exhibits the phenomenon of self-shielding. The center portion of the fuel is partially shielded from the neutron flux by the outer periphery. For this reason the local power generated at the center of the fuel pin is lower than the power generated in the outer portion of the fuel. This in turn affects the calculation of integral conductivity of the fuel. To account for self-shielding a power shape factor (PSF) was determined for E1AA. The power shape factor is a function of the neutron absorption cross sections of the mixed oxide and the geometry of the fuel pin.

The neutron absorption cross section of the mixed oxide fuel was calculated as follows:

Fuel Parameters:

$\% \mathrm{Pu}$

20.28

Density, \% T.D.

Enrichment, \% $\frac{U-235}{U-238+U-235}$

Weight

92.3

Length

$33.48 \mathrm{gm}$

Diameter

5.978 in.

Annulus
$0.2190 \mathrm{in.}$

0.073 in.
Isotopic Composition of Fuel:

$11-2.35$

U.238

0.901

1.000

Pu.239

0.9068

Pu.240

0.0849

Pu-241

0.0079

Pu-242

0.0004

Absorption Macroscopic Cross Section $(\Sigma a)$ for $n$ isotopes:

$$
\Sigma a=\sum_{i=1}^{n} N_{i} \sigma_{a i}
$$

where

$$
\begin{aligned}
N_{i}= & \text { atom density (atoms/cc) } \\
\sigma_{a i}= & \text { microscopic cross section of one } \\
& \text { atom of isotope } i \\
N_{i}= & \frac{\rho_{i} N a}{A_{i}} F_{i}
\end{aligned}
$$




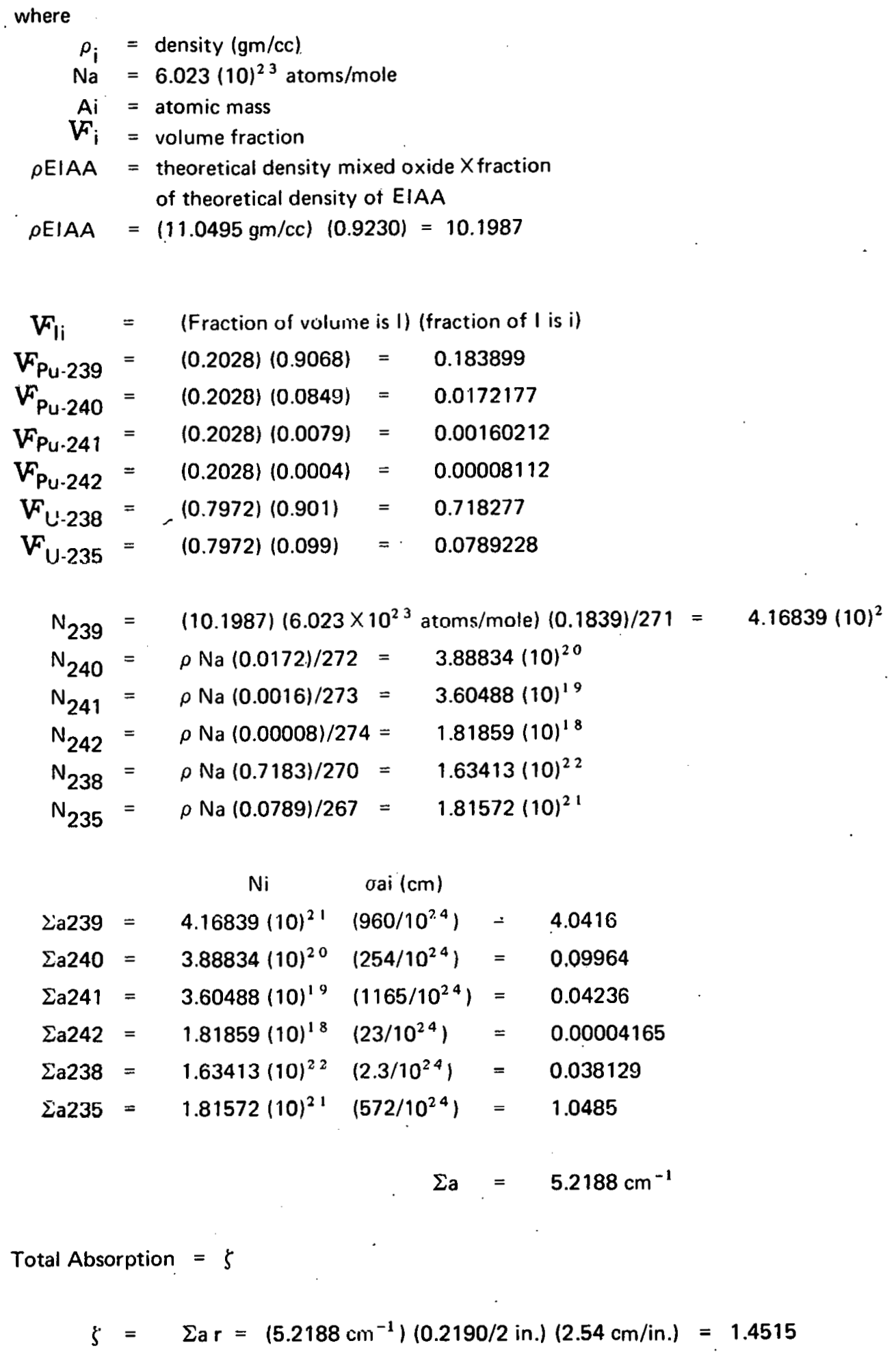


By using $\zeta$ on a Horwitz curve ${ }^{23}$ the self-shielding factor may be determined for various radial positions (Figure F-1).

The ratio of the factors at fuel center and fuel surface give the flux ratio of center to surface.

$$
\Phi c / \Phi s=\frac{0.160}{0.592}=0.271
$$

For this ratio a curve was determined which related the ratio of center annulus to fuel radius $(\beta)$ to the power shape factor (Figure F-2). ${ }^{23}$

$$
\begin{aligned}
& \beta=\frac{d \text { annulus }}{d \text { fuel }}=\frac{0.073}{0.2190}=0.333 \\
& \text { PSF }=0.522 \text { (From Figure F-2) }
\end{aligned}
$$




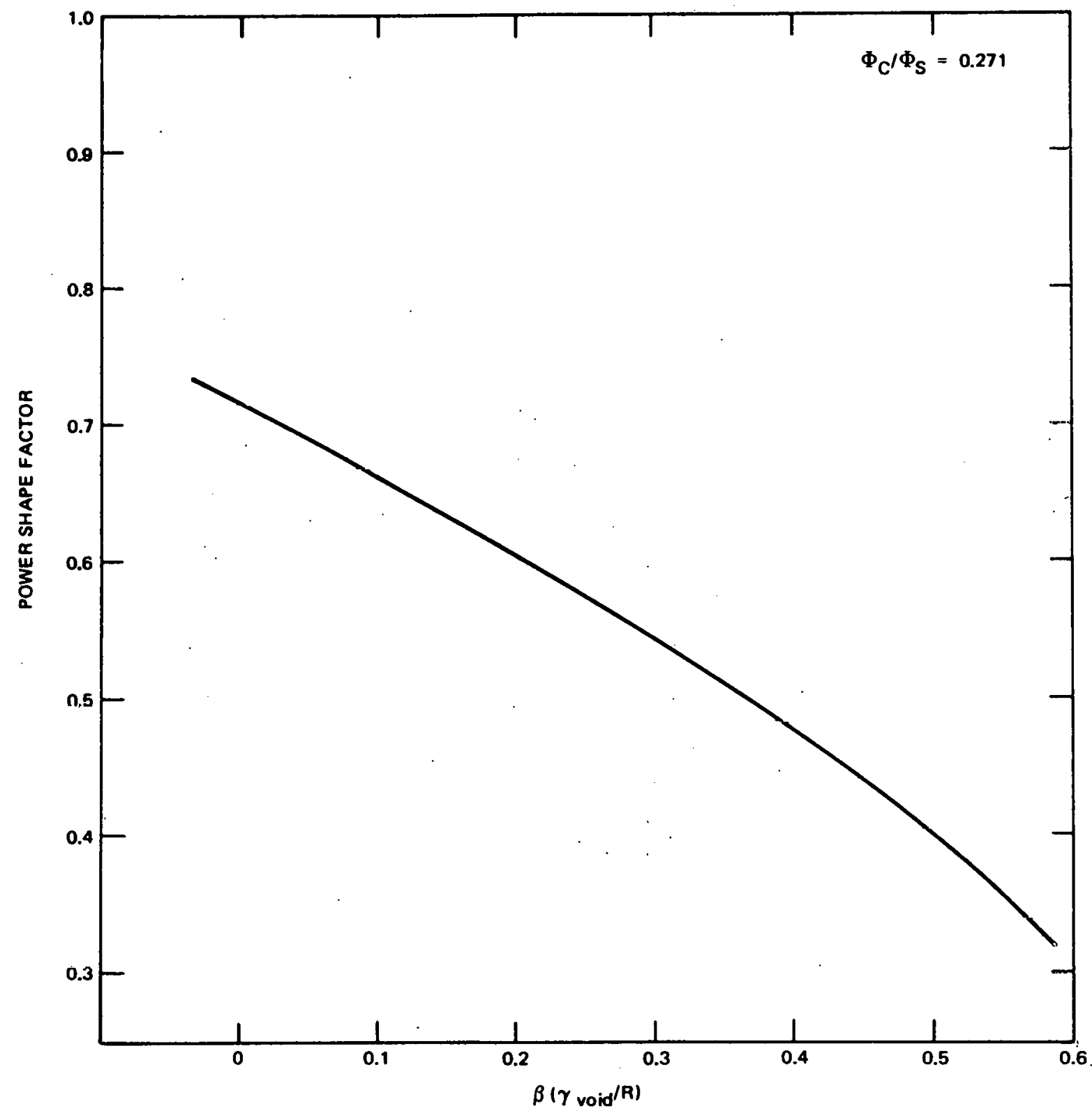

Figure F-2. Power Shape Factor for E1AA

.45 . 
GAP 13603

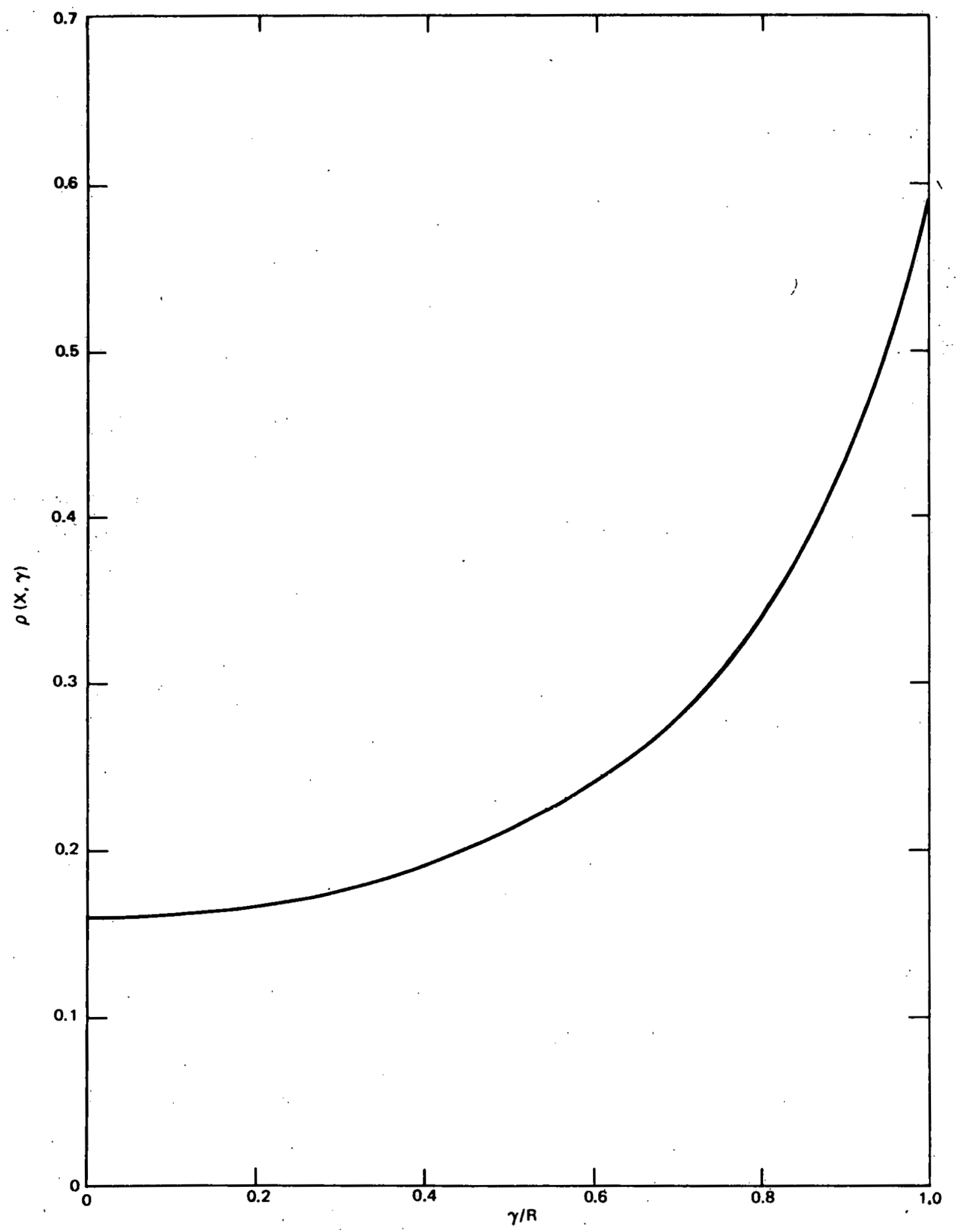

Figure F-1. E1AA Self Shielding Factor $R=0.1095$ Inch

$-46$ 


\section{ACKNOWLEDGMENT}

The authors wish to acknowledge the assistance of the following personnel in this experimental endeavor: N. C. Shirley-experimental design, H.S. Currie, G. R. Irwin, and W. L. Hall-capsule fabrication; R. M. Irvine and R. E. Smith-post-irradiation examination; W. L. Conant for his help during the capsule irradiation and the postirradiation thermocouple calibration test. Finally, we would like to extend our thanks to W. E. Baily, C. N. Spalaris, and

E. L. Zebroski for their direction and recommendations. 


\section{DISTRIBUTION}

Director, Contracts Division U.S. Atomic Energy Commission San Francisco Operations Office 2111 Bancroft Way

Berkeley, California 94704

RDT Site Office

U.S. Atomic Energy Commission General Electric Company

310 DeGuigne Drive

Sunnyvale, California 94086

Chief, California Patent Group

U. S. Atomic Energy Commission

San Francisco Operations Office

P. 0. Box 808

Livermore, California 94550

\section{Manager}

Westinghouse Electric Corporation

Advanced Reactors Division

P. O. Box 158

Madison, Pennsylvania 15663

Division of Reactor Development and Technology. Headquarters

U.S. Atomic Energy Commission :

Washington, D. C. 20545

Attn: Assistant Director, Engineering Standards

Division of Reactor Development and Technology. Headquarters

U.S. Atomic Energy Commission

Washington, D. C. 20545

Attn: Assistant Director, Nuclear Safety

Division of Reactor Development and Technology, Headquarters U. S. Atomic Energy Commission Washington, D. C. 20545

Attn: Assistant Director, Plant Engineering

Division of Reactor Development and Technology. Headquarters

U.S. Atomic Energy Commission Washington, D. C. 20545

Attn: Assistant Director. Program Analysis

Division of Reactor Development and Technology, Headquarters

U.S. Atomic Energy Commission

Washington, D. C. 20545

Attn: Assistant Director. Project Management
1 Division of Reactor Development and Technology, Headquarters U.S. Atomic Energy Commission Washington, D. C. 20545

Attn: Assistant Director. Reactor Engineering

Division of Reactor Development and Technology, Headquarters U. S. Atomic Energy Commission Washington, D. C. 20545

Attn: Assistant Director. Reactor Technology

Division of Reactor Development and Technology, Headquarters

U.S. Atomic Energy Commission Washington, D. C. 20545

Attn: Chief, Fuels and Materials Branch

Division of Reactor Development and Technology, Headquarters

U.S. Atomic Energy Commission Washington, D. C. 20545

Attn: Chief, Fuel Engineering Branch

Division of Reactor Development and Technology, Headquarters U. S. Atomic Energy Commission Waahington, D. C. 20545.

Attn: Chief, Reactor Vessels Branch

Assistant Director for

U. S. Atomic Energy Commission

P. O. Box 550

Richland, Washington 99352

RDT Site Office

U. S. Atomic Energy Commission Argonne National Laboratory Buillding 2

$1 \quad$ Argonne, llinois 60439

RDT Site Office

U.S. Atomic Energy Commission Atomics International P. O. Box 1446 Canoga Park, California 91304

2

RDT Site Office

U. S. Atomic Energy Commission Argonne National Laboratory

P. O. Box 2108

Idaho Falls, Idaho 83401 
RDT Senior Site Representative

U.S. Atomic Energy Commission P. O. Box 2325

San Diego, California 92112

Division of Naval Reactors

Chief, Nuclear Materials Branch

U. S. Atomic Energy Commission

Washington, D. C. 20545

Director

Division of Reactor Licensing

U. S. Atomic Energy Commission

Washington, D. C. 20545

Director

Metallurgy Division

Argonne National Laboratory

9700 South Cass Avenue

Argonne, Illinois 60439

Manager, FFTF Project

Pacific Northwest Laboratory

P. O. Box 999

Richland, Washington 99352

Manager

Chemistry and Metallurgy Division

Pacific Northwest Laboratory

P. O. Box 999

Richland, Washington 99352

RDT Site Office

U.S. Atomic Energy Commission

Oak Ridge National Laboratory

P. O. Box X

nak Ridge, Tennesssee 37830

Director

Division of Reactor Standards

U.S. Atomic Energy Commission

Washington, D. C. 20545

Division of Technical

Information Extension

U. S. Atomic Energy Commission

P. O. Box 62

Oak Ridge, Tennessee 37831

Direntor

LMFBR Program Office

Argonne National Laboratory

9700 South Cass Avenue

Aryunilite, Illinois 60439

Director

Chemical Engineering Division

Argonne National Laboratory

9700 South Cass Avenue

Argonne, Illinois 60439

* submitted with transmittal for AEC-426.

* * submitted for transmittal to recipient under UKAEAV USAEC and EURATOM/USAEC Fast Breeder Reactor Information Exchange arrangements.

2
1 FFTF Fuels Department

Pacific Northwest Laboratory

P. O. Box 999

Richland, Washington 99352

1 Division Leader (CMB)

Chemistry and Metallurgy Division

Los Alamos Scientific Laboratory

P. O. Box 1663

Los Alamos, New Mexico 87544

Director

Metallurgy and Materials

Science Division

Upton, New York 11973

Division Chief, M \& S D̃ivision

NASA - Lewis Research Center

21000 Brookpark Road

6

Cleveland, Ohio 44135

Director

Nuclear Safety Program

Oak Ridge National Laboratory

P. O. Box Y

1 Oak Ridge, Tennessee 37830

General Manager

Westinghouse Electric Corporation

Bettis Atomic Power Laboratory

P. O. Box 79

1 West Mifflin, Pennsylvania 15122

Associate Manager

Materials Engineering Department

Battelle Memorial Institute

Columbus Laboraturies

$2 \quad 505$ King Avenue

Columbus, Ohio 43201

Manager, Nuclear Laboratories

Combustion Engineering Inc.

$3 * .50 * \quad$ Nuclear Division

Prospect Hill Road

WIndsur, Cunnecticut 0G095

Manager, Plutonium Chemistry

and Ceramics Fuels Development

2 . Nuclear Materials and Equipment

Corporation

Plutonium Laboratory

Leechburg, Pennsylvania 15656

Head, Fuels and Materials

Atomic Power Development Associates

1911 rirst Street

Detroit, Michigan 48226

Director

Metals and Ceramics Division

Oak Ridge National Laboratory

P. O. Box X

Oak Ridge, Tennessee $\mathbf{3 7 8 3 0}$ 
Director, Liquid Metal

Engineering Center

Atomics International

P. O. Box 1449

Canoga Park, California 91304

Manager-Advanced Development Activity

General Electric Company

Knolls Atomic Power Laboratory

P. O. Box 1072

Schenectady, New York 12301

Director, LMFBR Technology Program

Atomics International

P. O. Box 309

Canoga Park, California 91304

Director

Nuclear Development Center

The Babcock and Wilcox Company

Atomic Energy Division

Lynchburg, Virginia 24501

Laboratory Assistant Director

Gulf General Atomic Incorporated

P. O. Box 608

San Diego, California 92112

Manager, Research

United Nuclear Corporation

Research and Engineering Center

Grasslands Road

Elmsford, New York 10523
$1 \quad$ K-2 Group Leader

Reactor Division

Los Alamos Scientific Laboratory

P. O. Box 1663

Los Alamos, New Mexico 87544

1 Westinghouse Electric Corporation

Technical Director

Advanced Reactors Division

P. O. Box 158

Madison, Pennsylvania 15663

1 Manager

Liquid Metal Information Center

Atomics International

P. O. Box 1449

Canoga Park, California 91304

1

Irradiation Coordinator

EBR-II Project

Argonne National Laboratory

P. O. Box 2528

Idaho Falls, Idaho 83401

1

Experiment Manager

EBR-II Project

Argonne National Laboratory

9700 South Cass Avenue

1 Argonne, Illinois 60439

Director

5

Reactor Analysis and Safety Division

Argonne National Laboratory

9700 South Cass Avenue

Argonne, Illinois, 60439 